\title{
Tetrabutylammonium tetrafluoroborate electrolyte as poly(vinyl chloride-co-vinyl acetate-co-2- hydroxypropyl acrylate) plasticizer: Thermal degradation and optical characteristics
}

Mahdy M. Elmahdy ( $\square$ elmahdy@mans.edu.eg)

Mansoura University https://orcid.org/0000-0002-9569-496X

Moustafa. T. Ahmed

Khalid A. Aldhafeeri

Maged A Azzam

Tarek Fahmy

\section{Research Article}

Keywords: PVVH, [TBA][BF4], ATR-FTIR, Thermal degradation, Glass temperature, Optical energy gap, Optical conductivity, Dielectric constant

Posted Date: March 7th, 2022

DOI: https://doi.org/10.21203/rs.3.rs-1416243/v1

License: (c) (i) This work is licensed under a Creative Commons Attribution 4.0 International License. Read Full License 
Tetrabutylammonium tetrafluoroborate electrolyte as poly(vinyl chloride-co-vinyl acetate-co-2-hydroxypropyl acrylate) plasticizer: Thermal degradation and optical characteristics

Mahdy M. Elmahdy ${ }^{\mathrm{a}, \mathrm{b}, *}$, Moustafa. T. Ahmed ${ }^{\mathrm{a}, \mathrm{c}}$, Khalid A. Aldhafeeri ${ }^{\mathrm{a}}$, Maged A Azzam ${ }^{\mathrm{d}}$, Tarek Fahmy ${ }^{\mathrm{c}}$

${ }^{a}$ Department of Physics, College of Science and Humanities, Prince Sattam bin Abdulaziz University, 11942, AlKharj, Saudi Arabia

${ }^{b}$ Department of Physics, Faculty of Science, Mansoura University, 35516, Mansoura, Egypt.

${ }^{c}$ Polymer Research Group, Department of Physics, Faculty of Science, Mansoura University, 35516 Mansoura, Egypt.

${ }^{d}$ Department of Chemistry, College of Science and Humanities, Prince Sattam bin Abdulaziz University, 11942 Alkharj, Saudi Arabia.

${ }^{*}$ Corresponding author

E-mail address: elmahdy@mans.edu.eg

\begin{abstract}
Casting method was employed to prepare films of poly(vinyl chloride-co-vinyl acetate-co-2hydroxypropyl acrylate) (PVVH) copolymer doped with different concentrations of tetrabutylammonium tetrafluoroborate $\left(\left[\mathrm{TBA}^{\mathrm{B}}\right]\left[\mathrm{BF}_{4}\right]\right)$ electrolyte. The interaction between copolymer and electrolyte was clearly evident in the reduction of FTIR peaks intensity at 1666 and $1729 \mathrm{~cm}^{-1}$ with increasing electrolyte concentration. This reduction was related to the deacetylation of PVVH by the electrolyte. Effect of deacetylation was also visible in the reduction of DTG/DTA peak temperature $\left(T_{\mathrm{p}}\right)$ of the second stage of the composites. The reduction of DSC glass transition temperature $\left(T_{\mathrm{g}}\right)$ from $344 \mathrm{~K}$ to 310 with increasing electrolyte content was another evidence of the deacetylation effect that reduces the interand intramolecular interaction maintaining flexibility of PVVH copolymer backbone to bend and slide more readily. Based on the aforementioned results, one can assume that $[\mathrm{TBA}]\left[\mathrm{BF}_{4}\right]$ electrolyte acts as an external plasticizer for PVVH that is internally plasticized by random copolymerization of vinyl chloride (VC) with vinyl acetate (VAc) and 2-hydroxypropyl acrylate (2HPA) to reduce the $T_{\mathrm{g}}$ of $\mathrm{VC}$ from 355 to $344 \mathrm{~K}$. Another reduction was observed in the optical energy gap $\left(E_{\mathrm{g}}\right)$ with increasing the electrolyte content. Linear and nonlinear optical parameters were estimated and discussed in terms of the single oscillator model. Besides, the optical conductivity $\left(\sigma_{\mathrm{op}}\right)$ and dielectric constant of all samples were investigated.
\end{abstract}

Keywords: PVVH, [TBA][BF 4 , ATR-FTIR, Thermal degradation, Glass temperature, Optical energy gap, Optical conductivity, Dielectric constant

\title{
1. Introduction
}

Nowadays, synthetic and natural polymer-based electrolytes have gained considerable interest and momentum in terms of studying their optical and electrical properties due to their use in many applications such as batteries, capacitors and fuel cells [1-3]. The nature of interaction of light with these new materials is of great interest especially when switching from solar cells to 
light-emitting devices [4]. Those polymers that possess unique optical properties encourage researchers to consider them for use in optical devices, LEDs as well as sensors [5].

Doping polymers with metals and electrolytes can enhance their physical properties paving the way for novel applications [2,6]. For example, PVVH/poly(ethyl methacrylate) blend filled with gold nanoparticles was used as corrosion inhibitor for API 5L X70 carbon steel [7]. Another study exploited the high sensitivity of PVVH to the fluctuations of environment temperature to fabricate nanogenerators from zinc oxide $(\mathrm{ZnO})$ nanowires that aligned vertically in the PVVH matrix [8]. Polymer electrolytes (PE) with low $T_{\mathrm{g}}$ achieve higher ionic conductivity and are favorable for commercial applications [9-12]. It was reported that the ionic conductivity increased by two orders of magnitude by using PE based on a low $T_{\mathrm{g}}$ poly(methyl siloxane) backbone [9]. The relationship between ionic conductivity and dielectric constant was also investigated by Imbrogno et al. [11] for poly(vinyl ether) lithium electrolytes and found an increase of ionic conductivity with increasing dielectric constant. The high electrical conductivity of PE is attributed to the lower lattice energy of electrolyte. The lower lattice energies of both polymer and electrolyte will increase the resulting polymer electrolyte stability. Hence, the dissolution of electrolyte in the polymer chains will be facilitated when the polymer has high dielectric and the salt has low lattice energy.

The quaternary tetrabutylammonium tetrafluoroborate $\left([\mathrm{TBA}]\left[\mathrm{BF}_{4}\right]\right)$ electrolyte is basically consisting of tetrabutylammonium (organic) cation and tetrafluoroborate (inorganic) anion and has the chemical form $\left[\mathrm{C}_{16} \mathrm{H}_{36} \mathrm{~N}\right]^{+}\left[\mathrm{BF}_{4}\right]^{-}$. It is water-soluble electrolyte with high-degree of interand intra-molecular hydrogen bonding. It has been successfully used extensively in electrochemistry, not only as a support electrolyte in aqueous and non-aqueous solvent systems, but also in many different electrochemical methods of analytical and industrial interest [13-15]. The poly(vinyl chloride-co-vinyl acetate-co-2-hydroxypropyl acrylate) (PVVH) is an amorphous copolymer with sensitive chemical structure to temperature change. It is widely used in solid-state sensors, polyions, membranes, nanogenerators and corrosion inhibitor [7,8]. In the literature, there are some articles that dealt with the investigation of relaxation phenomenon of PVVH as pure material or with another polymer as polymer blend [16-18] but there is a dearth of articles to study its optical properties [7,8,19-21].

In this contribution, we have prepared $\mathrm{PVVH} /\left[\mathrm{TBA}^{\mathrm{B}}\right]\left[\mathrm{BF}_{4}\right]$ copolymer electrolyte with different weight content of $[\mathrm{TBA}]\left[\mathrm{BF}_{4}\right]$ using casting method. The selection of PVVH was based on its flexibility and sensitivity to the change of temperature while $[\mathrm{TBA}]\left[\mathrm{BF}_{4}\right]$ electrolyte has numerous analytical and industrial applications. The purpose of this study is to trace the change of structure, thermal properties and optical characteristics of PVVH due to adding the electrolyte 
in different concentrations. The change in structure was probed by ATR-FTIR while TGA/DTA, DSC and UV-vis. measurements were employed to investigate the thermal and optical characteristics. TGA/DTA and DSC revealed reduction in peak $\left(T_{\mathrm{p}}\right)$ and glass transition $\left(T_{\mathrm{g}}\right)$ temperatures with increasing electrolyte concentration. On the other hand, UV-vis measurements demonstrated reduction in the optical energy gap $\left(E_{\mathrm{g}}\right)$ with increasing electrolyte content. Linear and nonlinear optical parameters were calculated for possible optical applications.

\section{Experimental}

\subsection{Materials and copolymer electrolyte preparation}

Poly (vinyl chloride-co-vinyl acetate-co-2-hydroxypropyl acrylate) (PVVH) with low molecular weight $\left(M_{\mathrm{n}} \sim 33000 \mathrm{~g} \mathrm{~mol}^{-1} ; 81 \mathrm{wt} \%\right.$ vinyl chloride (VC); $4 \mathrm{wt} \%$ vinyl acetate (VAc); 15 wt\% 2-hydroxylpropyl acrylate (2HPA)) was purchased from Sigma-Aldrich while Tetrabutylammonium tetrafluoroborate $\left(\left[\mathrm{TBA}^{\mathrm{B}}\right]\left[\mathrm{BF}_{4}\right]\right)$ with molecular weight of $329.27 \mathrm{~g} \mathrm{~mol}^{-1}$ was ordered from Merck.

Tetrahydrofuran (THF) was used as a common solvent for PVVH and [TBA] $\left[\mathrm{BF}_{4}\right]$ electrolyte. The latter was added to PVVH in different proportions (1wt \%, 2.5wt $\%$, 5wt $\%$, 10wt $\%$, $15 \mathrm{wt} \%$ and $20 \mathrm{wt} \%$ ) in THF with continuous stirring for about three hours to get homogeneous mixture. The mixture was poured into glass petri dish and kept in vacuum oven for about 24 hours at 50 ${ }^{\circ} \mathrm{C}$.

\subsection{Characterization techniques}

\subsubsection{ATR-FTIR spectroscopy}

Spectra of ATR-FTIR were recorded by Thermo Scientific iD5 ATR spectrometer in the wavenumber ranged from 500 to $4000 \mathrm{~cm}^{-1}$ and spectral resolution of $1 \mathrm{~cm}^{-1}$. Measurements were executed in ambient air at room temperature. Pure PVVH and its composites were measured by placing small amounts of the powder on top of diamond ATR crystal and collecting the spectra 100 times to achieve better signal to noise ratio.

\subsubsection{Thermogravimetric analysis (TGA/DTG)}

Thermal degradation of PVVH, $[\mathrm{TBA}]\left[\mathrm{BF}_{4}\right]$ and their composites was monitored by Netzsch TG 209 F1 Libra Thermogravimetric analyzer (TGA) in the temperature range from $23{ }^{\circ} \mathrm{C}$ to $800{ }^{\circ} \mathrm{C}$ in steps of $10{ }^{0} \mathrm{C} \mathrm{min}-1$ under nitrogen atmosphere. Appropriate amount of the sample was placed in crucibles made of alumina $\left(\mathrm{Al}_{2} \mathrm{O}_{3}\right)$ and the nitrogen gas was flow at a constant rate of $20 \mathrm{ml}$ $\min ^{-1}$.

\subsubsection{Differential scanning calorimetry (DSC)}

Netzsch DSC 214 was employed to probe the thermal characteristics of PVVH with heating/cooling rate of $10{ }^{\circ} \mathrm{C} \mathrm{min}{ }^{-1}$. The samples were first heated from 298 to $473 \mathrm{~K}$ and then 
cooled down to $223 \mathrm{~K}$ with the same rate. The heat flow was recorded during the cooling run in order to overcome the thermal history of the samples and adsorbed water.

\subsubsection{UV-vis spectroscopy}

Absorption of UV-vis radiation by $\mathrm{PVVH}$ and its composites was traced by UV-5200 spectrophotometer in the wavelength range from 200 to $1100 \mathrm{~nm}$ and bandwidth of $1 \mathrm{~nm}$. UV-vis spectra were collected in ambient air at room temperature.

\section{Results and discussion}

\subsection{ATR-FTIR spectroscopy}

Fig. 1a shows the ATR-FTIR transmission spectra for PVVH and its composites in the wavenumber range 4000-500 $\mathrm{cm}^{-1}$ at room temperature. Symmetric and asymmetric C-H stretching vibrations of methylene groups are detected at high wavenumbers from 2972 to 2980 $\mathrm{cm}^{-1}$ while the hydroxyl groups $(\mathrm{OH})$ of 2-hydroxypropylacrylate (2HPA) perform stretching vibrations at $3415 \mathrm{~cm}^{-1}$ [21-24]. The intensity of the higher wavenumber peaks $(2877,2908$, 2938 and $2961 \mathrm{~cm}^{-1}$ ) increases with increasing the electrolyte content due to the formation of hydrogen bond with free $\mathrm{OH}$ [24]. The two sharp peaks appear at $1666 \mathrm{~cm}^{-1}$ and $1729 \mathrm{~cm}^{-1}$ are assigned to stretching vibrations of carbonyl groups $(\mathrm{C}=\mathrm{O})$ of 2HPA and vinyl acetate (VAc) monomers, respectively[25-27].
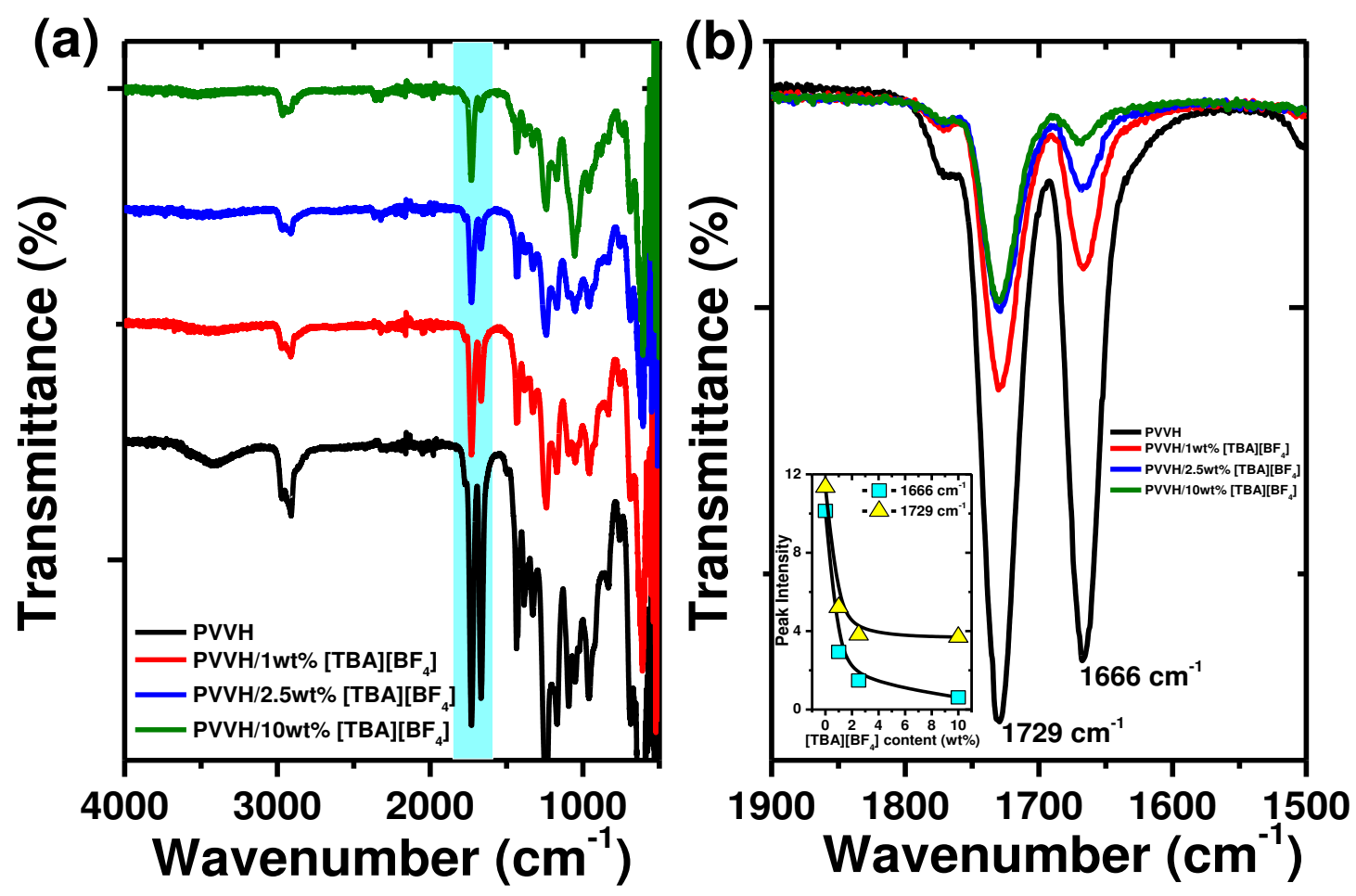

Fig. 1 (a) ATR-FTIR transmission spectra for pure PVVH (black line) and its composites with [TBA][BF4] weight content of $1 \mathrm{wt} \%$ (red line), $2.5 \mathrm{wt} \%$ (blue line) and $10 \mathrm{wt} \%$ (olive line). The highlighted intense bands at 1666 and $1729 \mathrm{~cm}^{-1}$ in (a) are zoomed in plot (b). Inset of (b) is the variation of $1666 \mathrm{~cm}^{-1}$ (squares) and 1729 $\mathrm{cm}^{-1}$ (up triangles) peaks intensities with the electrolyte content. Solid lines in the inset are guide for the eye. 
Surprisingly, the intensity of the two peaks (Fig. 1b and inset of (b)) decrease rapidly with increasing the electrolyte content indicating reduction in acetic acid in the composites. The elimination of acetic acid leads to the formation of double bonds in the composites [26]. The results indicate that, $[\mathrm{TBA}]\left[\mathrm{BF}_{4}\right]$ has the ability to deacetylate the $\mathrm{PVVH}$ in different degrees. Previous results showed similar effect of the deacetylation of chitin in tetrabutylammonium hydroxide [TBA][OH] [28]. The lower wavenumber peaks at 1435, 1377 and 1234 are related to the $\mathrm{CH}_{2}, \mathrm{CH}_{3}$ and $\mathrm{C}-\mathrm{O}$ vibrations of VAc while peaks at 1387,1172 and $1049 \mathrm{~cm}^{-1}$ are corresponding to the $\mathrm{CH}_{3}, \mathrm{O}-\mathrm{C}=\mathrm{O}$ and $\mathrm{C}-\mathrm{O}-\mathrm{C}$ vibrations of 2HPA monomers [25,27]. The remaining vibrations of vinyl chloride (VC) monomers are located at 1426, 1331, 1093 and 613$691 \mathrm{~cm}^{-1}$ for $\mathrm{CH}_{2}, \mathrm{CH}, \mathrm{C}-\mathrm{C}$ and $\mathrm{C}-\mathrm{Cl}[29,30]$. It was observed that the $\mathrm{C}-\mathrm{Cl}$ peaks intensities at 613 and $691 \mathrm{~cm}^{-1}$ decrease with increasing electrolyte content.

\subsection{Kinetics of thermal degradation}

Thermal properties of polymers and their composites give valuable information regarding toughness, stiffness, miscibility with other compounds and stability. Thermogravimetric analysis (TGA) is usually used to characterize various polymeric materials. Its thermogram displays the weight decreasing pattern of the materials during thermal decompositions. Differential thermal gravimetric (DTG) curves clearly exhibit the maximum/peak temperature of decomposition at every step of thermal decomposition. In TGA, the mass change of a material is recorded with temperature at a constant heating rate. In general, two different types of thermal degradation processes are realized in polymeric materials and they are called depolymerization of the chain and random decomposition. The latter occurs by rupturing the chain at random points leading to dispersed mixture of fragments while the former is essentially a reverse polymerization process during which monomer units are released from the end of a chain or at a weak linker. Both processes cause the material to lose mass at certain high temperatures.

Fig. 2a-f displays the TGA/DTG of PVVH, $\left[\mathrm{TBA}^{\mathrm{B}}\right]\left[\mathrm{BF}_{4}\right]$ and their composites in temperature range from 23 to $800{ }^{\circ} \mathrm{C}$ in steps of $10{ }^{\circ} \mathrm{C} \mathrm{min}-1$. The TGA behavior of $\mathrm{PVVH}$ can be distinguished into four stages. The first stage (I) is observed in temperature range $\sim 23-214{ }^{\circ} \mathrm{C}$ with weight loss of $2.95 \%$ and peak temperature $\left(T_{\mathrm{p}}\right)$ of $129^{\circ} \mathrm{C}$. This stage can be attributed to the evaporation of $\mathrm{H}_{2} \mathrm{O}$ and residual solvent. The major chemical reaction in the second stage (II) $\left(218-351^{\circ} \mathrm{C}\right)$ is the dechlorination reaction with a main degradation product of $\mathrm{HCl}$ and small quantity of $\mathrm{Cl}_{2}$. This stage includes also the elimination of acetic acid at about $250{ }^{\circ} \mathrm{C}$ with an overall weight loss of $57.27 \%$ and $T_{\mathrm{p}}$ of $277^{\circ} \mathrm{C}$ [31-33]. 


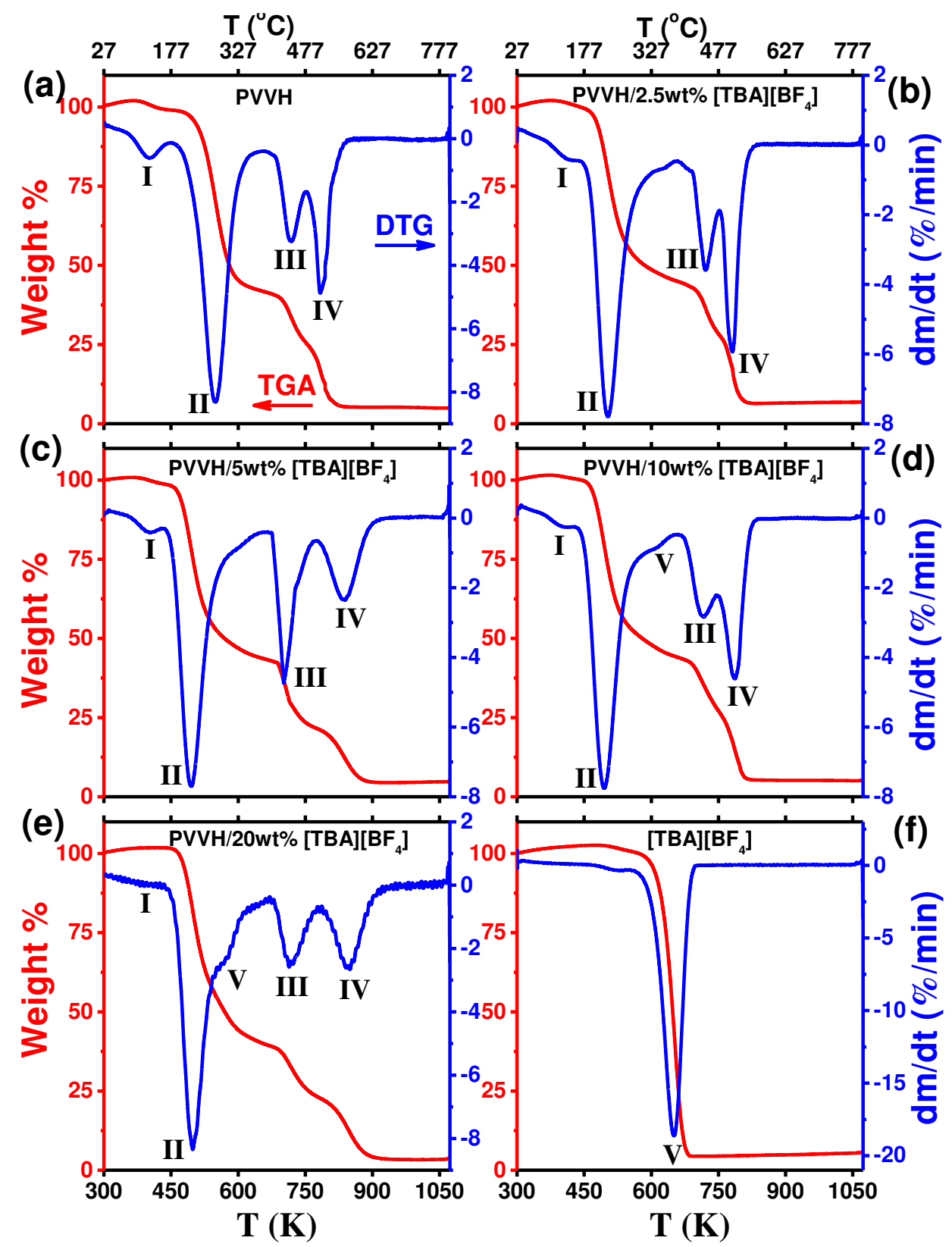

Fig. 2 TGA/DTG measurements for PVVH (a), $[\mathrm{TBA}]\left[\mathrm{BF}_{4}\right]$ (f) and their composites with [TBA] $\left[\mathrm{BF}_{4}\right]$ weight content of $2.5 \mathrm{wt} \%$ (b), $5 \mathrm{wt} \%$ (c), $10 \mathrm{wt} \%$ (d) and $20 \mathrm{wt} \%$ (e).

The elimination of $\mathrm{HCl}$ and acetic acid will leave behind longer polyene chains and increase the probability of radical propagation and molecular reactions leading to $\mathrm{C}-\mathrm{Cl}$ bond cleavage [34-36]. At temperature above $310^{\circ} \mathrm{C}$, the chain radical mechanism becomes relevant and the melting of C-C or C-H bonds occurs [31]. The third degradation step (III) of PVVH is observed between 427 and $483{ }^{\circ} \mathrm{C}$ with weight loss of $15.9 \%$ and $T_{\mathrm{p}}$ of $446{ }^{\circ} \mathrm{C}$. The fourth stage (IV) (491$561^{\circ} \mathrm{C}$ ) reveals weight loss and $T_{\mathrm{p}}$ of $20.87 \%$ and $510{ }^{\circ} \mathrm{C}$, respectively. Thermal degradation of polyene sequences can be executed in the third and fourth stages because the volatile aliphatic and aromatic compounds are produced via the intramolecular cycle of conjugate sequences [37]. From the temperature range of each degradation stage, it is obvious that the second degradation 
stage is the fastest and most prominent one. Therefore, the kinetics of thermal degradation of this stage will be investigated in more details as we will see below.

On the other hand, the PVVH/[TBA] $\left[\mathrm{BF}_{4}\right]$ composites display similar behavior of thermal degradation as pure PVVH however with slight change in weight loss. Surprisingly, the second stage related to dehydrochlorination and removal of acetic acid (deacetylation) demonstrates remarkable reduction in $T_{\mathrm{p}}$ from $277{ }^{\circ} \mathrm{C}$ to $237{ }^{\circ} \mathrm{C}$ just by adding $1 \mathrm{wt} \%$ of [TBA][BF $]$ to $\mathrm{PVVH}$. This reduction continues until reach $216{ }^{\circ} \mathrm{C}$ at $15 \mathrm{wt} \%$ of $[\mathrm{TBA}]\left[\mathrm{BF}_{4}\right]$. The rapid decrease in $T_{\mathrm{p}}$ with increasing electrolyte concentration is most probably due to the deacetylation effect of vinyl acetate monomers $(\mathrm{VA})$ by $[\mathrm{TBA}]\left[\mathrm{BF}_{4}\right]$. This means that $[\mathrm{TBA}]\left[\mathrm{BF}_{4}\right]$ electrolyte promotes the removal of acetic acid along with temperature. Deacetylation of chitin in tetrabutylammonium hydroxide $[\mathrm{TBA}][\mathrm{OH}]$ was recently reported by $\mathrm{Ma}$ et al. [28] and found an increase of deacetylation by four times as the temperature increased from $20{ }^{\circ} \mathrm{C}$ to $80{ }^{\circ} \mathrm{C}$. Besides reduction in $T_{\mathrm{p}}$, the composites with high content of electrolyte are decomposed in five stages as shown in Fig. $2 \mathrm{~d}$ and e. The decomposition of butylammonium ions (Fig. 2f) can be carried out at high temperature yielding an amine that can interact with $\mathrm{HClO}_{4}$ produced from thermal degradation of PVVH forming amine perchlorate $[13,38]$. Based on the classical Hoffmann degradation of quaternary ammonium salts produces $\mathrm{HBF}_{4}$, which in turn leads to the appearance of $\mathrm{HF}$ and $\mathrm{BF}_{3}[39]$. The peak temperature and percentage of weight loss for all degradation stages for all samples are compiled in Table 1.

Table 1 TGA/DTG peak temperature $\left(T_{p}\right)$ and the percentage of weight loss $(\%)$ for PVVH, $[\mathrm{TBA}]\left[\mathrm{BF}_{4}\right]$ and their composites.

\begin{tabular}{|c|c|c|c|c|c|c|c|c|c|c|}
\hline \multirow[b]{2}{*}{ Sample } & \multicolumn{2}{|c|}{ Stage I } & \multicolumn{2}{|c|}{ Stage II } & \multicolumn{2}{|c|}{ Stage III } & \multicolumn{2}{|c|}{ Stage IV } & \multicolumn{2}{|c|}{ Stage V } \\
\hline & $\begin{array}{c}\boldsymbol{T}_{\boldsymbol{p}} \\
{ }^{\circ} \mathbf{C}(\mathbf{K})\end{array}$ & $\begin{array}{c}\text { Weight } \\
(\%)\end{array}$ & $\begin{array}{c}T_{p} \\
{ }^{\circ} \mathbf{C}(\mathbf{K})\end{array}$ & $\begin{array}{c}\text { Weight } \\
(\%)\end{array}$ & $\begin{array}{c}T_{p} \\
{ }^{\circ} \mathbf{C}(\mathbf{K})\end{array}$ & $\begin{array}{c}\text { Weight } \\
(\%)\end{array}$ & $\begin{array}{c}T_{p} \\
\circ \mathbf{C}(\mathbf{K})\end{array}$ & $\begin{array}{c}\text { Weight } \\
(\%)\end{array}$ & $\begin{array}{c}\boldsymbol{T}_{\boldsymbol{p}} \\
{ }^{\circ} \mathbf{C}(\mathbf{K})\end{array}$ & $\begin{array}{c}\text { Weight } \\
(\%)\end{array}$ \\
\hline PVVH & $129(402)$ & 2.95 & $277(550)$ & 57.27 & $446(719)$ & 15.9 & $510(783)$ & 20.87 & - & - \\
\hline $\mathrm{PVVH} / 1 \mathrm{wt} \%[\mathrm{TBA}]\left[\mathrm{BF}_{4}\right]$ & $141(414)$ & 4.17 & $237(510)$ & 58.86 & $448(721)$ & 16.66 & $537(810)$ & 21.37 & - & - \\
\hline $\mathrm{PVVH} / 2.5 \mathrm{wt} \%[\mathrm{TBA}]\left[\mathrm{BF}_{4}\right]$ & $150(423)$ & 2.69 & $230(503)$ & 56.95 & $448(721)$ & 16.67 & $509(782)$ & 21.52 & - & - \\
\hline $\mathrm{PVVH} / 5 \mathrm{wt} \%[\mathrm{TBA}]\left[\mathrm{BF}_{4}\right]$ & $131(404)$ & 2.18 & $223(496)$ & 47.61 & $429(702)$ & 14.87 & $565(838)$ & 16.41 & - & - \\
\hline $\mathrm{PVVH} / 10 \mathrm{wt} \%[\mathrm{TBA}]\left[\mathrm{BF}_{4}\right]$ & $128(401)$ & 1.97 & $222(495)$ & 57.69 & $448(721)$ & 18.48 & $514(787)$ & 18.89 & $319(592)$ & - \\
\hline $\mathrm{PVVH} / 15 \mathrm{wt} \%[\mathrm{TBA}]\left[\mathrm{BF}_{4}\right]$ & - & - & $216(489)$ & 52.2 & $443(716)$ & 12.71 & $558(831)$ & 16.19 & $306(597)$ & - \\
\hline $\mathrm{PVVH} / 20 \mathrm{wt} \%[\mathrm{TBA}]\left[\mathrm{BF}_{4}\right]$ & - & - & $226(499)$ & 52.6 & $441(714)$ & 16.81 & $557(830)$ & 18.71 & $304(577)$ & 9.96 \\
\hline$[\mathrm{TBA}]\left[\mathrm{BF}_{4}\right]$ & - & - & - & - & - & - & - & - & $378(651)$ & 96.93 \\
\hline
\end{tabular}

The effect of deacetylation of PVVH by the addition of electrolyte is also evident in the reduction of $T_{\mathrm{g}}$ for $\mathrm{PVVH}$ from $\sim 344 \mathrm{~K}$ to 310 with increasing [TBA] $\left[\mathrm{BF}_{4}\right]$ concentration from 10 to $20 \mathrm{wt} \%$ as shown in Fig. 3. Deacetylation causes change of the PVVH conformation by reducing the inter- and intramolecular interaction maintaining flexibility of polymer backbone to bend and slide more readily. This result corresponds with previous reports for the reduction of $T_{\mathrm{g}}$ with increasing the degree of deacetylation for chitosan [40]. 


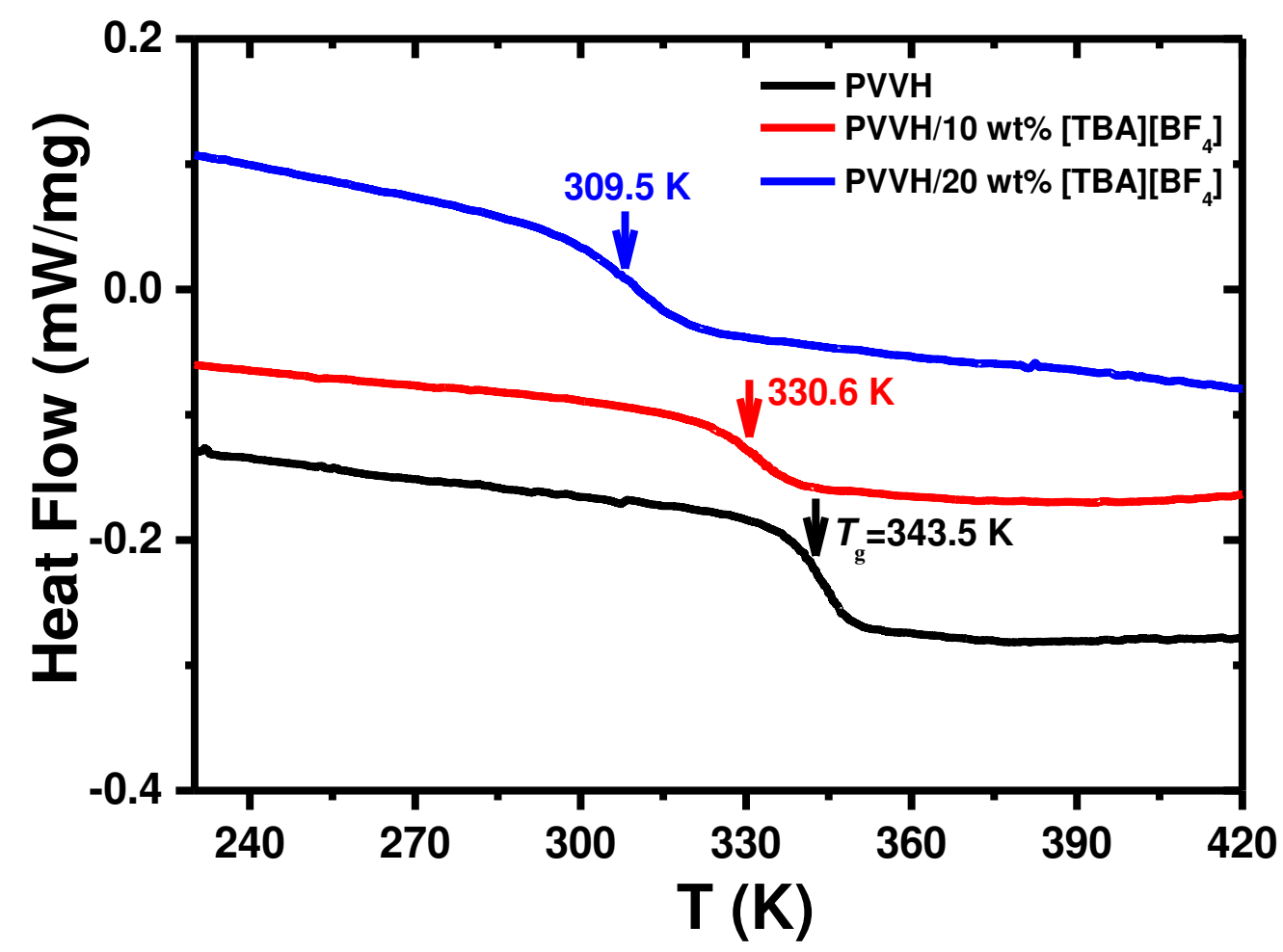

Fig. 3 DSC traces for pure PVVH (black line) and PVVH/[TBA][BF 4$]$ composites with [TBA] $\left[\mathrm{BF}_{4}\right]$ weight content of $10 \mathrm{wt} \%$ (red line) and $20 \mathrm{wt} \%$ (blue line) measured on cooling from $473 \mathrm{~K}$ to $223 \mathrm{~K}$ with a cooling rate of $10{ }^{\circ} \mathrm{C} \mathrm{min}^{-1}$. The downward vertical arrows give the locations of $T_{\mathrm{g}}$ for $\mathrm{PVVH}$ and the corresponding composites.

Based on the DSC results, one can assume that $[\mathrm{TBA}]\left[\mathrm{BF}_{4}\right]$ electrolyte acts as an external plasticizer for PVVH that is internally plasticized by random copolymerization of VC with VAc and 2HPA monomers to reduce the $T_{\mathrm{g}}$ of $\mathrm{VC}$ from 355 to $344 \mathrm{~K}$. Further reduction in $T_{\mathrm{g}}$ from $344 \mathrm{~K}$ to $310 \mathrm{~K}$ is achieved by adding $\left[\mathrm{TBA}^{2}\left[\mathrm{BF}_{4}\right]\right.$ to PVVH. Two conceivable scenarios for PVVH plasticization by $[\mathrm{TBA}]\left[\mathrm{BF}_{4}\right]$. The first scenario is based on the lubrication theory in which plasticizer molecules minimize segment-segment interaction of PVVH and consequently keep the polymer chains apart and maintain flexibility. Furthermore, it can act as lubricant that allow the PVVH chains to slide over each other. The second scenario is based on the free volume theory in which polymer chains are closely packed and restricted in motion in the glassy state. Heating the polymer above $T_{\mathrm{g}}$ creates more free volume which is occupied by plasticizer resulting in lowering $T_{\mathrm{g}}$ by separating PVVH chains [41]. The spectacular reduction in $T_{\mathrm{g}}$ of PVC due to external and internal plasticizers have been report by many researchers [42-46]. For example, Li et al. [44] have incorporated four plasticizers to PVC chain via glutamic acid linker and found strong depression of $T_{\mathrm{g}}$ for PVC- triethylene glycol esters compared to PVC-alkyl esters. Moreover, they found a correlation between the plasticizer length and $T_{\mathrm{g}}$ i.e., longer length plasticizer correlate with lower $T_{\mathrm{g}}$. In addition, TGA measurements for these compounds 
demonstrated that the PVC-triethylene glycol esters degrade at lower temperatures than the PVCalkyl esters. Navarro et al. [47] have used Trichlorotriazine (TCTA)- based sodium thiolates with different aliphatic chains as an external plasticizer that is covalently bonded with PVC. They observed reduction in $T_{\mathrm{g}}$ below $0{ }^{\circ} \mathrm{C}$ when commercial polyetheramines, terminated Jeffamines and polypropylene glycol were used. Similar results were report by the same group for the conventional PVC- di-2-ethylhexylphthalate blends [48].

The kinetics of thermal degradation process can be expressed by the theory of activated complexes as follows $[49,50]$

$$
K=\frac{\gamma e k_{B} T}{h} \exp \left(\frac{\Delta S}{R}\right) \exp \left(-\frac{E_{a}}{R T}\right)
$$

Here, $K$ is the degradation rate while $k_{B}, h$ and $R$ are the Boltzmann, Planck and universal gas constants, respectively. $\Delta S$ and $E_{\mathrm{a}}$ are the activation of entropy and activation energy of decomposition, respectively, whereas $\gamma, e(=2.7183)$ and $T$ are the coefficient of transmission (unity for monomolecular reaction), Neper number and the absolute temperature, respectively. Eq. (1) is based on Arrhenius equation as

$$
K=f \exp \left(-\frac{E_{a}}{R T}\right)
$$

Where $f$ is the frequency factor that can be expressed as follows

$$
f=\frac{\gamma e k_{B} T}{h} \exp \left(\frac{\Delta S}{R}\right)
$$

Hence, $\Delta S$ can be estimated as follows

$$
\Delta S=2.303\left[\log \left(\frac{f h}{e k_{B} T}\right)\right] R
$$

And

$$
E_{a}=\Delta H+R T
$$

Where $\Delta H$ is the activation of enthalpy. Therefore, the Gibbs free energy $(\Delta H)$ can be determined as follows

$$
\Delta G=\Delta H-T \Delta S
$$

The thermodynamic parameters $\left(E_{a}, \Delta H, \Delta S\right.$, and $\left.\Delta G\right)$ of each decomposition stage of PVVH and its composites can be estimated graphically by applying the Coats-Redfern method using order of reaction $n=1$ [51]

$$
\log \left[\frac{-\log (1-g)}{T^{2}}\right]=\log \frac{f R}{\delta E_{a}}\left[1-\frac{2 R T}{E_{a}}\right]-\frac{E_{a}}{2.303 R T}
$$


Here, $\delta$ is rate of heating and $g$ is the extent of reaction for each stage and described by the following equation

$$
g=\frac{m_{0}-m_{i}}{m_{0}-m_{f}}
$$

Here, $m_{0}$ and $m_{f}$ are the initial and final/residual masses, respectively, while $m_{i}$ is the mass at time/temperature $i$.

For $2 R T / E_{\mathrm{a}}<<1$, Eq. (7) becomes

$$
\log \left[\frac{-\log (1-g)}{T^{2}}\right]=\log \frac{f R}{\delta E_{a}}-\frac{E_{a}}{2.303 R T}
$$

A plot of $\log \left[-\log (1-g) / T^{2}\right]$ against $1000 / T$ (Fig. 4a-f) will results in a straight line with slope $=-$ $E_{\mathrm{a}} / 2.303 R$ from which $E_{\mathrm{a}}$ is obtained. On the other hand, the frequency factor $f$ is determined from the intercept of the straight line with $y$-axis at $\log f R / \delta E_{\mathrm{a}}$.

The kinetic parameters for dehydrochlorination ( $\mathrm{HCl}$ removal) and deacetylation (acetic acid removal) of PVVH and its composites are calculated from stage II (Fig. 4a-f) and given in Table 2. The parameters of the olefinic backbone breakage at high temperature $\left(>400{ }^{\circ} \mathrm{C}\right)$ are not calculated due to the overlapping between stages III and IV. The activation energy for acids removal $\left(E_{a}\right)$ is found to increase with increasing electrolyte content in PVVH revealing an enhancement of thermal stability for the composite samples. The value of $E_{\mathrm{a}}$ for pure [TBA][BF 4$]$ $(\sim 194 \mathrm{~kJ} / \mathrm{mol})$ is close to the reported one by Prasad et al. [13] $(233 \mathrm{~kJ} / \mathrm{mol})$. The difference between the two values might come from the different heating and gas flow rates. The impact of internal plasticization of VC by random copolymerization with VAc and 2HPA is evident in the low value of $E_{\mathrm{a}}(81.51 \pm 0.34 \mathrm{~kJ} / \mathrm{mol})$ for PVVH compared to the most recently reported value for PVC $(119.8 \pm 12.4 \mathrm{~kJ} / \mathrm{mol})$ [52]. The enthalpy and entropy values (Table 2) tell us about the changes in the internal structure or organization during the process of degradation. The negative values of $\Delta S$ reveal that the reaction rate is slower than normal.

Table 2 C-R kinetic parameters for PVVH, [TBA] $\left[\mathrm{BF}_{4}\right]$ and their composites.

\begin{tabular}{|l|c|c|c|c|c|}
\hline \multicolumn{1}{|c|}{ Sample } & $\begin{array}{c}E_{\mathrm{a}} \\
(\mathrm{kJ} / \mathrm{mol})\end{array}$ & $\begin{array}{c}f \\
\left(\mathrm{~s}^{-1}\right)\end{array}$ & $\begin{array}{c}\Delta H \\
(\mathrm{~kJ} / \mathrm{mol})\end{array}$ & $\begin{array}{c}\Delta S \\
(\mathrm{~kJ} / \mathrm{mol} . \mathrm{K})\end{array}$ & $\begin{array}{c}\Delta G \\
(\mathrm{~kJ} / \mathrm{mol})\end{array}$ \\
\hline PVVH & $81.51 \pm 0.34$ & $4.05 \times 10^{4}$ & 76.94 & -0.170 & 170.53 \\
\hline PVVH/1wt\% [TBA] $\left[\mathrm{BF}_{4}\right]$ & $90.64 \pm 0.19$ & $1.85 \times 10^{6}$ & 86.39 & -0.138 & 156.72 \\
\hline PVVH/2.5wt\% [TBA] $\left[\mathrm{BF}_{4}\right]$ & $90.54 \pm 0.69$ & $2.26 \times 10^{6}$ & 86.36 & -0.136 & 154.72 \\
\hline PVVH/5wt\% [TBA] $\left[\mathrm{BF}_{4}\right]$ & $90.44 \pm 0.99$ & $2.66 \times 10^{6}$ & 86.31 & -0.135 & 153.10 \\
\hline PVVH/10wt\% [TBA] $\left[\mathrm{BF}_{4}\right]$ & $89.35 \pm 0.81$ & $2.05 \times 10^{6}$ & 85.23 & -0.137 & 152.87 \\
\hline PVVH/15wt\% [TBA] $\left[\mathrm{BF}_{4}\right]$ & $108.53 \pm 1.71$ & $2.94 \times 10^{8}$ & 104.46 & -0.095 & 151.01 \\
\hline PVVH/20wt\% [TBA] $\left[\mathrm{BF}_{4}\right]$ & $123.19 \pm 1.28$ & $7.17 \times 10^{9}$ & 119.04 & -0.069 & 153.37 \\
\hline$\left[\right.$ TBA] $\left[\mathrm{BF}_{4}\right]$ & $194.17 \pm 0.08$ & $1.39 \times 10^{13}$ & 188.76 & -0.008 & 194.02 \\
\hline
\end{tabular}



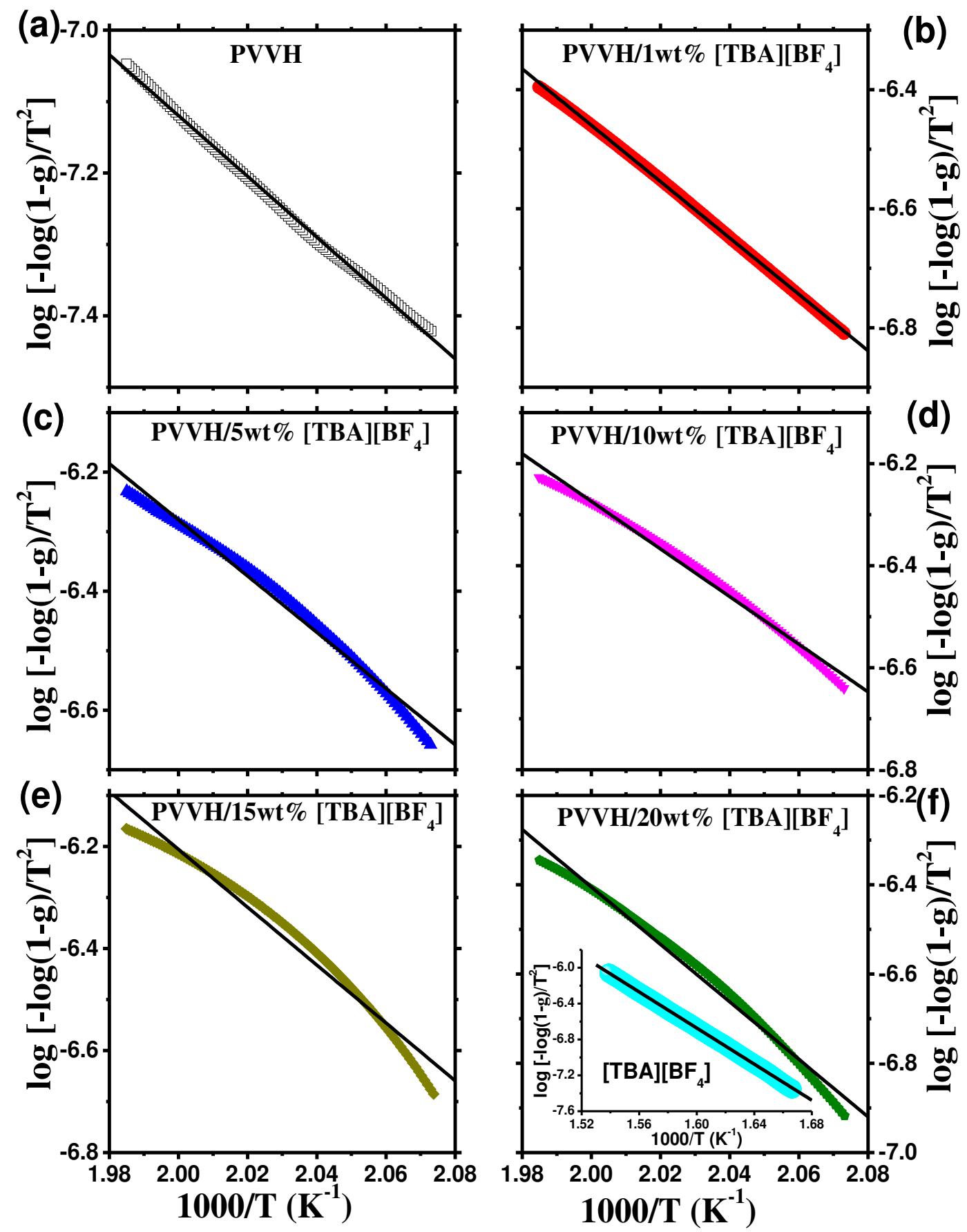

Fig. 4 Coats-Redfern (C-R) plots for thermal degradation of stage II for PVVH (a), [TBA][BF $]$ (inset of (f)) and their composites with [TBA] $\left[\mathrm{BF}_{4}\right]$ weight content of $1 \mathrm{wt} \%$ (b), $5 \mathrm{wt} \%$ (c), 10 $\mathrm{wt} \%$ (d), $15 \mathrm{wt} \%$ (e) and $20 \mathrm{wt} \%$ (f). Linear fits (solid lines) give the activation energy of decomposition $\left(E_{\mathrm{a}}\right)$ and the frequency factor $(f)$ (see Table 2$)$.

As clearly seen in Table 2, there is a correlation between $E_{\mathrm{a}}$ and $f$ i.e., a large value of $E_{\mathrm{a}}$ is accompanied by a large value of $f$ and vice versa, a phenomenon often called the compensation or isokinetic effect or $\theta$-rule $[53,54]$ as shown in Fig. 5a. Also, a linear relationship is observed between entropy $(\Delta S)$ and enthalpy $(\Delta H)$ which indicates the direct proportionality between these two quantities as shown in Fig. 5b. The linear relationship between $\Delta H$ and $\Delta S$ confirms the 
existence of compensation phenomenon in $\mathrm{PVVH} /[\mathrm{TBA}]\left[\mathrm{BF}_{4}\right]$ composites. The compensation effect reveals that the enthalpy variation accompanying the changes in temperature as the molecular cleavage of the polymer occurs during the decomposition process is compensated by the variation in the enthalpy change [54].

The isokinetic temperature $\left(T_{\text {iso }}\right)$, isokinetic rate constant $\left(k_{\text {iso }}\right)$ and $E_{\text {a }}$ are correlated by the following expression $[53,54]$

$\ln f=\ln k_{\text {iso }}+\frac{E_{a}}{R T_{\text {iso }}}$
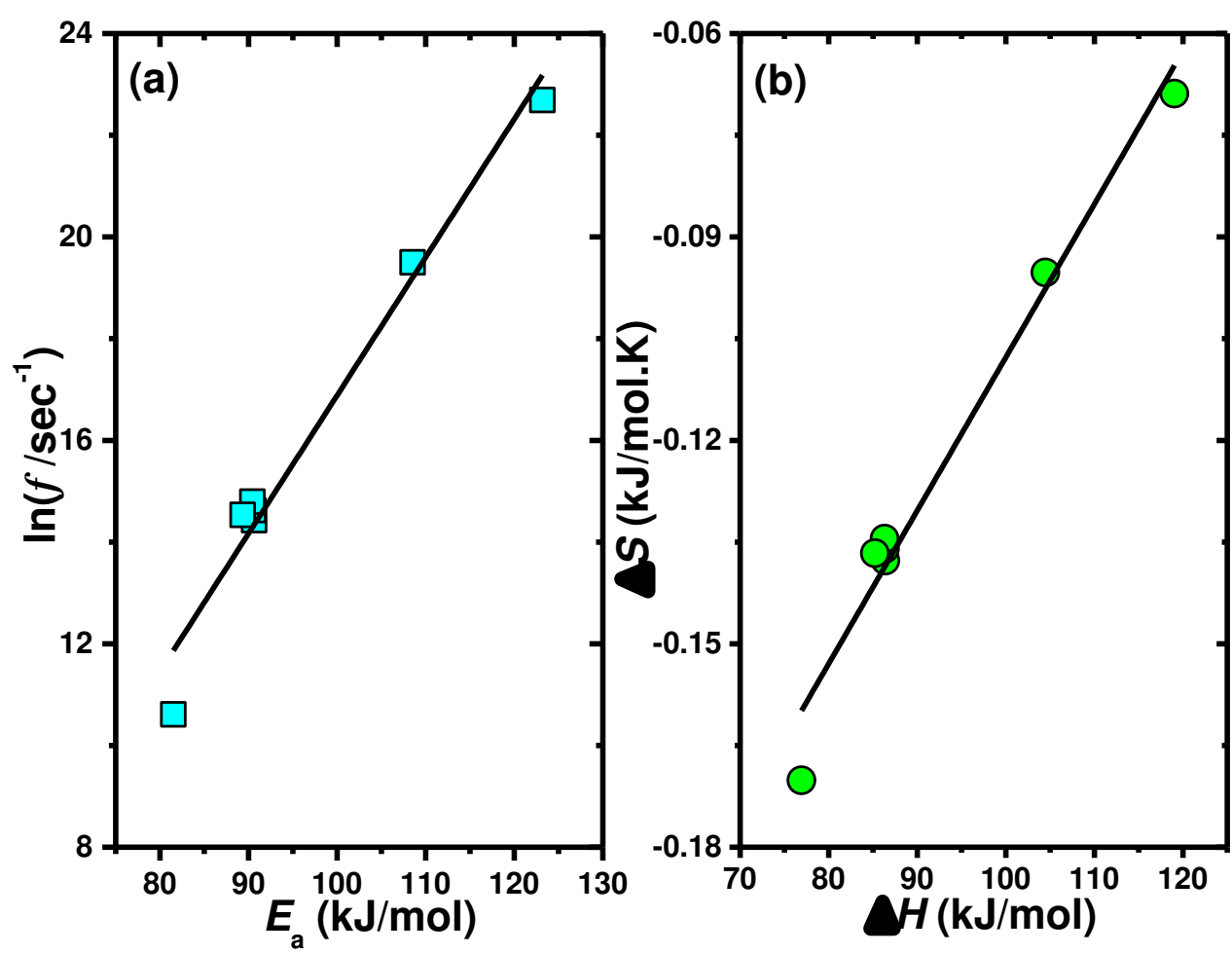

Fig. 5 (a) Activation energy $\left(E_{\mathrm{a}}\right)$-frequency factor $(f)$ compensation plot. (b) Enthalpy $(\Delta H)$ entropy $(\Delta S)$ compensation plot.

The isokinetic temperature $\left(T_{\text {iso }}\right)$ is the temperature at which the chemical reactions proceed at the same rate. At $T>T_{\text {iso, }}$, faster reactions hold higher activation energies and at $T<T_{\text {iso, }}$, the faster reactions proceed with lower activation energies. In order to get $T_{\text {iso }}$ and $k_{\text {iso }}$ for the composites, a linear fit is made by Eq. (10) to the data points shown in Fig. 5a. The fit produces the following expression $\ln f=-10.27025( \pm 1.97458)+0.27156( \pm 0.02031) E$ with slope $\left(=1 / R T_{\text {iso }}\right)$ and intercept $\left(=\ln k_{\text {iso }}\right)$ of 0.27156 and -10.27025 , respectively. The latter gives $k_{\text {iso }}$ of $3.46 \times 10^{-5} \mathrm{~s}^{-1}$ while the former give $T_{\text {iso }}$ of $442.9 \mathrm{~K}$. Similarly, the linear fit of $\Delta H$ - $\Delta S$ (Fig.5b) gives analogous expression $\Delta S=-0.33374( \pm 0.01548)+0.00226\left( \pm 1.66294 \times 10^{-4}\right) \Delta H$. Values in brackets represent the error limit. 
Compensation effect of PVVH and PVVH/PMMA blend was reported using thermally stimulated depolarization current (TSDC) and found $T_{\text {iso }}$ of $352 \mathrm{~K}[18,55]$. Thermal degradation of PVC and PVAc and their blends were investigated by Sivalingam et al. [30] using TGA. They reported $T_{\text {iso }}$ of 533 and $716 \mathrm{~K}$ for the acid and olefinic removal, respectively, for PVC degradation with the corresponding $k_{\text {iso }}$ of $4.9 \times 10^{-4}$ and $2.3 \times 10^{-4} \mathrm{~s}^{-1}$. On the other hand, the PVAc demonstrated $T_{\text {iso }}$ of 583 and $709 \mathrm{~K}$ with $k_{\text {iso }}$ of $6.9 \times 10^{-4}$ and $2.1 \times 10^{-4} \mathrm{~s}^{-1}$, for acetic acid and olefinic removal, respectively. They concluded from their study that after removal of $\mathrm{HCl}$ and acetic acid the backbone of both polymers is identical and therefore will have the same stage of degradation.

\subsection{UV-vis spectroscopy}

The absorption spectra of PVVH/[TBA] $\left[\mathrm{BF}_{4}\right]$ composite samples were recorded in the wavelength $(\lambda)$ range 200-950 $\mathrm{nm}$ and displayed in Fig. 6a.
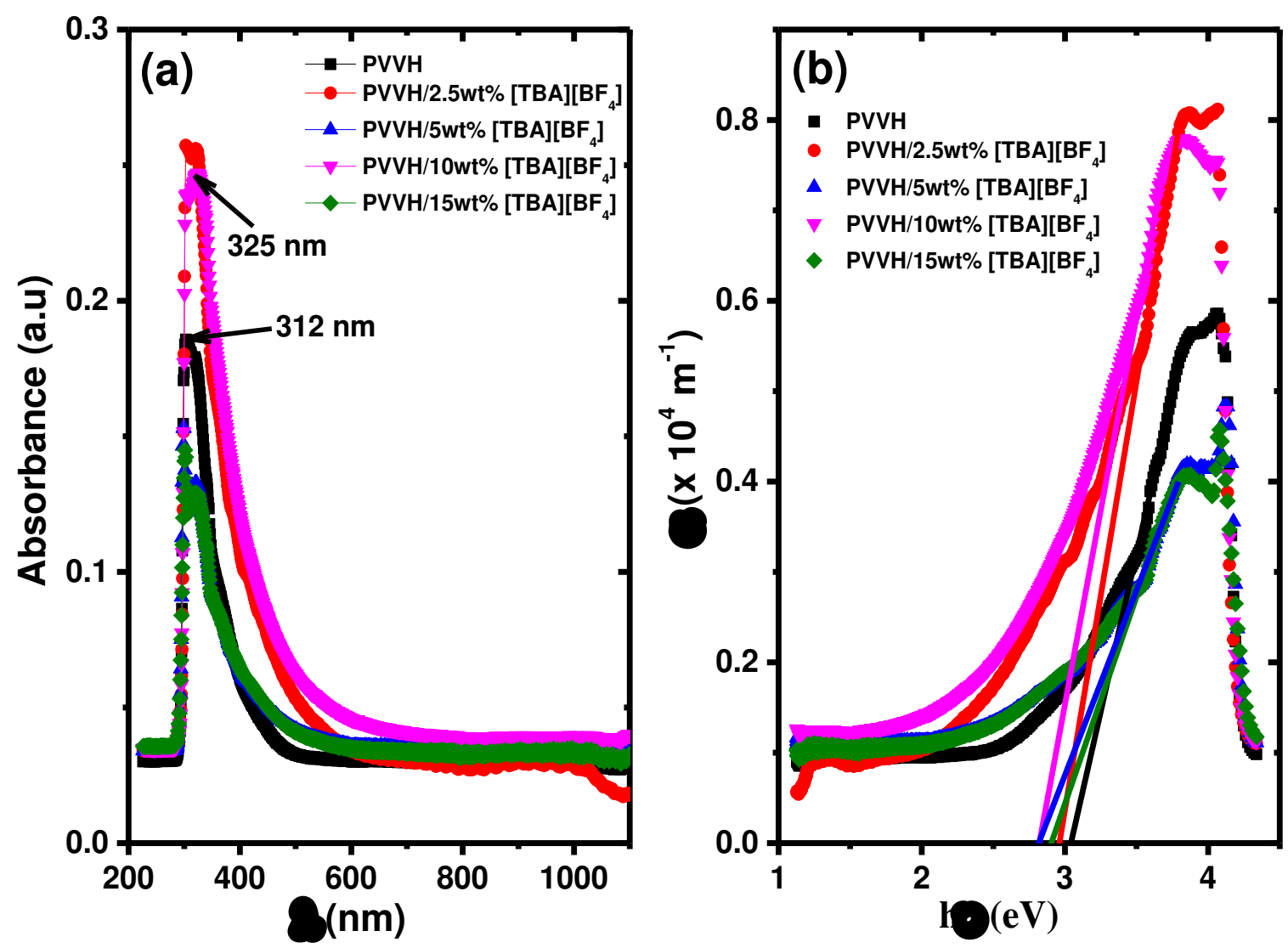

Fig. 6 a) Absorbance against wavelength $(\lambda)$ and b) Absorption coefficient $(\alpha)$ against incident photo energy $(h v)$ for pure PVVH and PVVH/[TBA] $\left[\mathrm{BF}_{4}\right]$ composite samples. Solid lines in (b) represent the fit of the linear part of the plot.

Pure PVVH demonstrates an absorptions peak at $312 \mathrm{~nm}$ that is shifted to higher wavelength (325 nm) for PVVH/[TBA] $\left[\mathrm{BF}_{4}\right]$ composite samples. This absorption peak is attributed to $\pi-\pi^{*}$ transition [21] and its shift indicates reduction in $E_{\mathrm{g}}$. The exponential increase in absorption 
coefficient $\alpha(=2.303 A / d, A$ : absorbance and $d$ : sample thickness $)$ with incident photon energy $(h v)$ is the main characteristic of absorption edge $\left(E_{\text {edge }}\right)$ that is related to severe discontinuity in absorption spectrum when the absorbed photon energy match an electronic transition. The absorption edge $\left(E_{\text {edge }}\right)$ is estimated by fitting the linear part of $\alpha-h v$ plot (Fig. 6b) and then extrapolating the fitting line to $\alpha=0$. The values of $E_{\text {edge }}$ decrease with increasing the electrolyte content in PVVH matrix (Table 3).

The width of band tail or Urbach tail energy $\left(E_{U}\right)$ can be estimated from the exponential dependence of $\alpha-h v$ relation [56,57]

$\alpha=\alpha_{0} \exp \left(\frac{h v}{E_{U}}\right)$

Here, $\alpha_{0}$ is the preexponential factor.
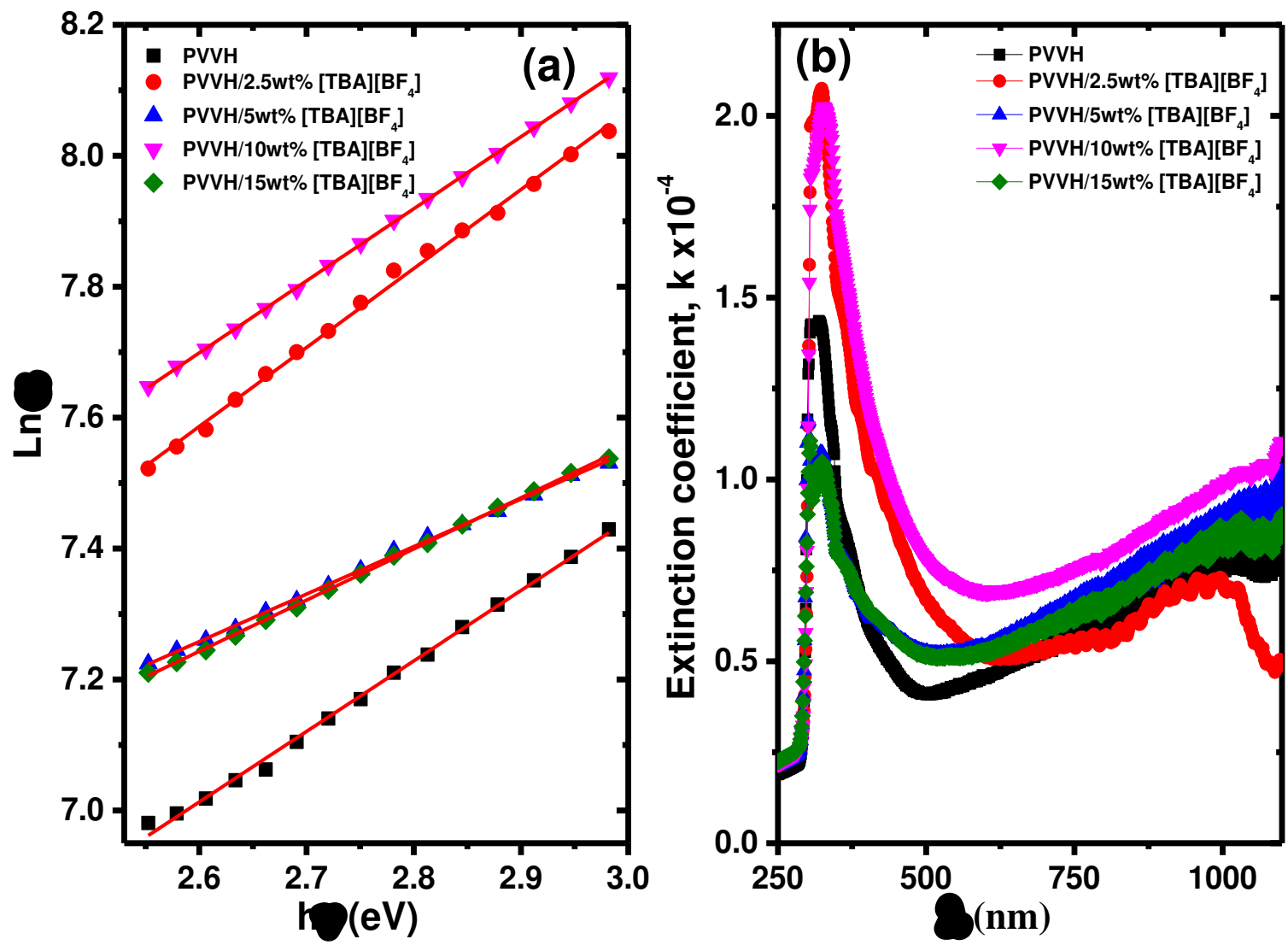

Fig. 7 a) Ln $\alpha$ against incident photo energy $(h v)$ and b) Extinction coefficient $(k)$ against wavelength $(\lambda)$ for pure $\mathrm{PVVH}$ and $\mathrm{PVVH} /[\mathrm{TBA}]\left[\mathrm{BF}_{4}\right]$ composite samples.

Fig. 7a shows the Ln $\alpha$-hv linear relationship for all samples. The linear fit of data points gives $E_{\mathrm{u}}$-values between $\sim 0.93$ and $1.38 \mathrm{eV}$ (Table 3). The increase of $E_{\mathrm{u}}$ with [TBA][BF concentration can be interpreted by the fact that an increase in electrolyte content may lead to defects and imperfections in the amorphous structure of PVVH, a condition that may increase localized states within the forbidden gap. Our results are consistent with previous work for 
PVVH filled with cobalt chloride [20]. The calculated values of $E_{U}$ can be used to get the steepness parameter $(\beta)$ (Table 3) that characterize the broadening of $E_{\text {edge }}$ due to electron/exciton-photon interaction according to the following relation

$\beta=\frac{k_{B} T}{E_{U}}$

Here, $T(=300 \mathrm{~K})$ is the absolute temperature and $k_{B}$ is Boltzmann constant.

Table 3 The optical parameters for PVVH/[TBA] $\left[\mathrm{BF}_{4}\right]$ composite samples.

\begin{tabular}{|l|c|c|c|c|c|}
\hline Optical Parameters & Pure PVVH & $\begin{array}{c}\mathrm{PVVH} / 2.5 \mathrm{wt} \% \\
{[\mathrm{TBA}][\mathrm{BF} 4]}\end{array}$ & $\begin{array}{c}\mathrm{PVVH} / 5 \mathrm{wt} \% \\
{[\mathrm{TBA}][\mathrm{BF} 4]}\end{array}$ & $\begin{array}{c}\mathrm{PVVH} / 10 \mathrm{wt} \% \\
{[\mathrm{TBA}]\left[\mathrm{BF}_{4}\right]}\end{array}$ & $\begin{array}{c}\mathrm{PVVH} / 15 \mathrm{wt} \% \\
{[\mathrm{TBA}][\mathrm{BF} 4]}\end{array}$ \\
\hline$E_{\text {edge }}(\mathrm{eV})$ & $3.04 \pm 0.09$ & $2.96 \pm 0.06$ & $2.90 \pm 0.05$ & $2.82 \pm 0.22$ & $2.81 \pm 0.13$ \\
\hline$E_{\mathrm{U}}(\mathrm{eV})$ & $0.93 \pm 0.01$ & $0.83 \pm 0.01$ & $1.38 \pm 0.01$ & $0.91 \pm 0.01$ & $1.28 \pm 0.01$ \\
\hline$\beta$ & 0.028 & 0.031 & 0.018 & 0.028 & 0.020 \\
\hline$E_{\mathrm{g}-\text { direct }}(\mathrm{eV})$ & $2.68 \pm 0.08$ & $2.51 \pm 0.05$ & $2.42 \pm 0.06$ & $2.32 \pm 0.15$ & $2.27 \pm 0.10$ \\
\hline$E_{\mathrm{g} \text {-indirect }}(\mathrm{eV})$ & $3.45 \pm 0.11$ & $3.38 \pm 0.04$ & $3.37 \pm 0.05$ & $3.36 \pm 0.11$ & $3.34 \pm 0.07$ \\
\hline$\varepsilon \mathrm{L}$ & $4.61 \pm 0.03$ & $6.62 \pm 0.04$ & $4.17 \pm 0.02$ & $7.17 \pm 0.05$ & $4.29 \pm 0.02$ \\
\hline$N / m^{*}\left(\times 10^{67} \mathrm{~m}^{-3} \mathrm{~kg}^{-1}\right)$ & 11.4 & 17.7 & 7.9 & 19.7 & 8.5 \\
\hline$\omega_{\mathrm{p}}\left(\times 10^{20} \mathrm{rad} / \mathrm{s}\right)$ & 5.75 & 7.16 & 4.78 & 7.56 & 4.97 \\
\hline$E_{0}(\mathrm{eV})$ & $3.97 \pm 0.01$ & $4.08 \pm 0.03$ & $4.46 \pm 0.02$ & $4.00 \pm 0.02$ & $4.44 \pm 0.02$ \\
\hline$E_{d}(\mathrm{eV})$ & $3.11 \pm 0.01$ & $5.35 \pm 0.04$ & $4.77 \pm 0.02$ & $5.37 \pm 0.03$ & $4.71 \pm 0.02$ \\
\hline$F(\mathrm{eV})^{2}$ & $12.35 \pm 0.04$ & $21.85 \pm 0.20$ & $21.30 \pm 0.12$ & $21.48 \pm 0.14$ & $20.93 \pm 0.11$ \\
\hline$M_{-1}$ & $0.784 \pm 0.002$ & $1.309 \pm 0.012$ & $1.68 \pm 0.006$ & $1.342 \pm 0.008$ & $1.062 \pm 0.005$ \\
\hline$M_{-3},(\mathrm{eV})^{-2}$ & $0.049 \pm 0.001$ & $0.078 \pm 0.002$ & $0.054 \pm 0.001$ & $0.084 \pm 0.001$ & $0.054 \pm 0.001$ \\
\hline$n_{0}$ & $1.336 \pm 0.001$ & $1.519 \pm 0.004$ & $1.438 \pm 0.002$ & $1.531 \pm 0.003$ & $1.436 \pm 0.002$ \\
\hline$\varepsilon_{s}$ & $1.784 \pm 0.002$ & $2.309 \pm 0.012$ & $2.068 \pm 0.006$ & $2.342 \pm 0.009$ & $2.062 \pm 0.005$ \\
\hline$\eta\left(\times 10^{-37} \mathrm{C}^{2} \mathrm{~m}^{2} / \mathrm{J}\right)$ & 2.18 & 3.21 & 2.77 & 3.26 & 2.75 \\
\hline$\eta^{\prime}\left(\times 10^{-27} \mathrm{~m}^{3}\right)$ & 1.96 & 2.88 & 2.49 & 2.93 & 2.48 \\
\hline$\lambda_{0}\left(\times 10^{-7} \mathrm{~m}\right)$ & 3.12 & 3.04 & 2.77 & 3.10 & 2.79 \\
\hline$s_{\mathrm{o}}\left(\times 10^{13} \mathrm{~m}^{-2}\right)$ & 0.81 & 1.42 & 1.38 & 1.39 & 1.36 \\
\hline$\chi^{(1)}$ & 0.062 & 0.104 & 0.085 & 0.107 & 0.084 \\
\hline$\chi^{(3)}\left(\times 10^{-15} \mathrm{e} . \mathrm{s} . \mathrm{u}.\right)$ & 2.71 & 21.12 & 9.36 & 23.27 & 9.11 \\
\hline$n_{2}\left(\times 10^{-13} \mathrm{e} . \mathrm{s} . \mathrm{u}\right)$ & 0.76 & 5.24 & 2.45 & 5.73 & 2.39 \\
\hline
\end{tabular}

The optical characterization of materials is generally governed by the interaction between the materials and electric field of incident electromagnetic waves. The behavior of the extinction coefficient $k(=\alpha \lambda / 4 \pi)$ with the wavelength gives a reasonable indication of the certainty that these interactions have taken place, and thus it describes the propagation and velocity of the electromagnetic wave through the materials. Fig. $7 \mathrm{~b}$ depicts the variation of $k$ with wavelength for $\mathrm{PVVH} /[\mathrm{TBA}]\left[\mathrm{BF}_{4}\right]$ composite samples. The behavior of all samples demonstrates a significant decrease in $k$ values as $\lambda$ increase from $\sim 280$ to $500 \mathrm{~nm}$ followed by an increase at longer wavelengths. Furthermore, the composites exhibit higher $k$ values compared to the pristine 
PVVH. The decrease in $k$ values confirms that these materials allow electromagnetic waves to pass through without any damping or decay in this region. On the other hand, the increase of $k$ at higher wavelengths indicates to more scattering of photons are taken place with increasing $[\mathrm{TBA}]\left[\mathrm{BF}_{4}\right]$ in PVVH matrix. Similar behavior has been found for amorphous semiconductors [58].
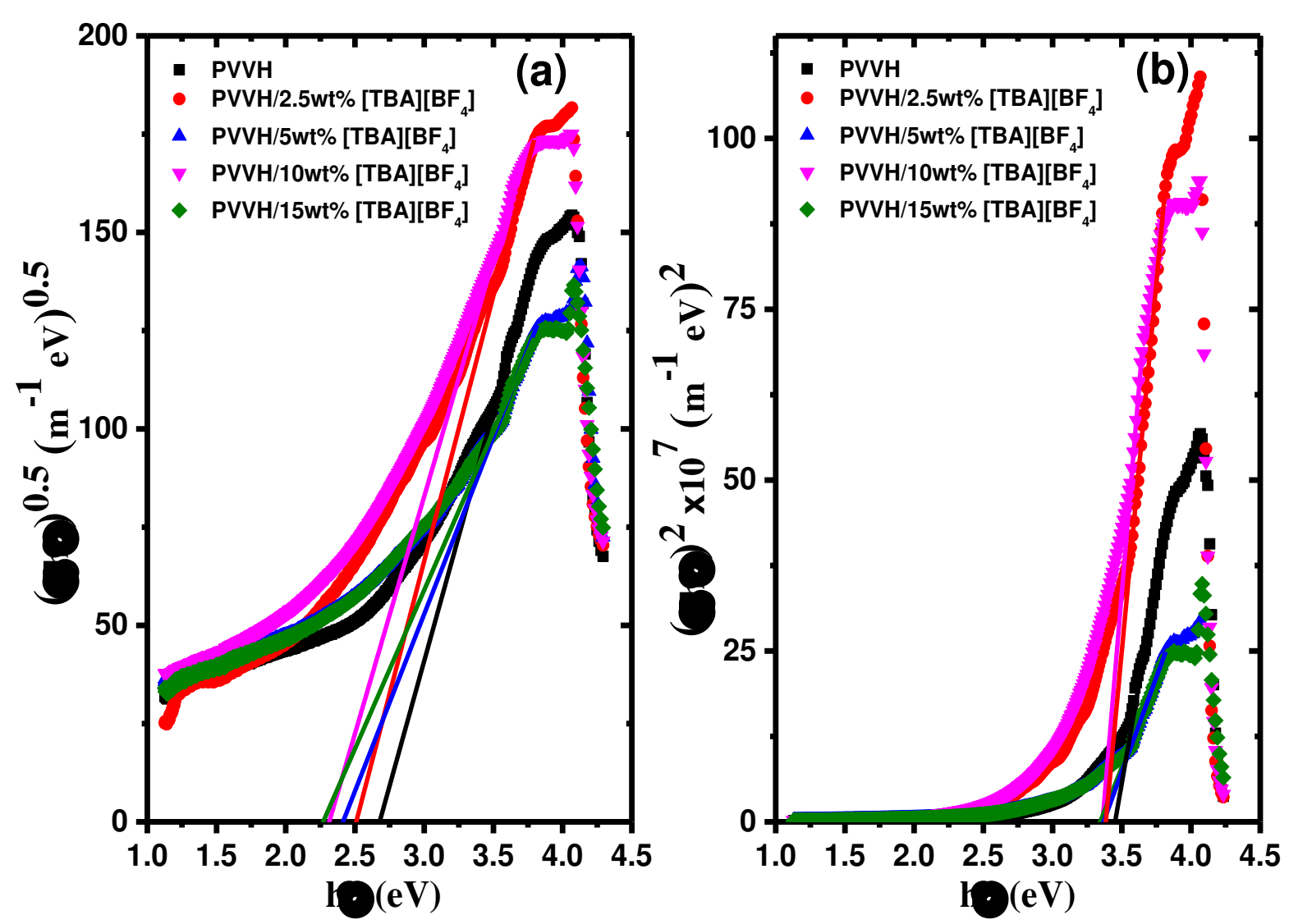

Fig. 8 a) $(\alpha h v)^{0.5}$ versus $h v$ b) $(\alpha h v)^{2}$ versus $h v$ for PVVH and PVVH/[TBA][BF 4 composite samples.

The optical energy gap $\left(E_{\mathrm{g}}\right)$ is an essential parameter for determining the amount of absorbed solar spectrum by a photovoltaic cell. It is the difference in energy between the top and bottom of the valence and conduction bands, respectively. The $E_{\mathrm{g}}, \alpha$ and $h v$ are interrelated through Tauc equation [59]

$\alpha h v=B\left(h v-E_{g}\right)^{x}$

Where $B$ is the band tail parameter and the index $x$ identifies the type of electronic transition. The latter takes $1 / 2$ (direct) and 2 (indirect) for allowed transitions while forbidden transitions are given $x$-values of $3 / 2$ (direct) and 3 (indirect), respectively. Extrapolating the linear fitted parts of Fig. $8 \mathrm{a}$ and $\mathrm{b}$ to $(\alpha h v)^{0.5}$ and $(\alpha h v)^{2}=0$ will give the values of direct $\left(E_{\mathrm{g} \text {-direct }}\right)$ and indirect $\left(E_{\mathrm{g} \text { - }}\right.$ indirect) $E_{\mathrm{g}}$ for PVVH and its composites (Table 3). A significant decrease in $E_{\mathrm{g} \text {-direct }}$ and $E_{\mathrm{g} \text {-indirect }}$ is observed with increasing the content of electrolyte in PVVH matrix indicating that the composite 
samples become more semiconducting in nature. Reduction in $E_{\mathrm{g}}$ could be explained based on the fact that incorporating amounts of doping would form charge transfer complexes (CTCs) in PVVH network leading to an increase of optical conductivity and decrease in $E_{\mathrm{g}}$ by giving additional charges to the network [60].

Investigating the refractive index $(n)$ for the performance of optical systems is very important and necessary to match or optimize the numerical aperture of the optical reduction system at all points in any optical path. The refractive index control of optical polymers makes it suitable for a wide range of industrial and medical applications such as optical communications, anti-reflective coatings, light-emitting diodes, organic solar cells and polymer lenses. Reflectance $(R)$, transmittance ( $T)$ and $n$ are related to each other through the following relation [61]

$n=\frac{1+\sqrt{R}}{1-\sqrt{R}}, \quad R=1-\sqrt{T e^{A}}$
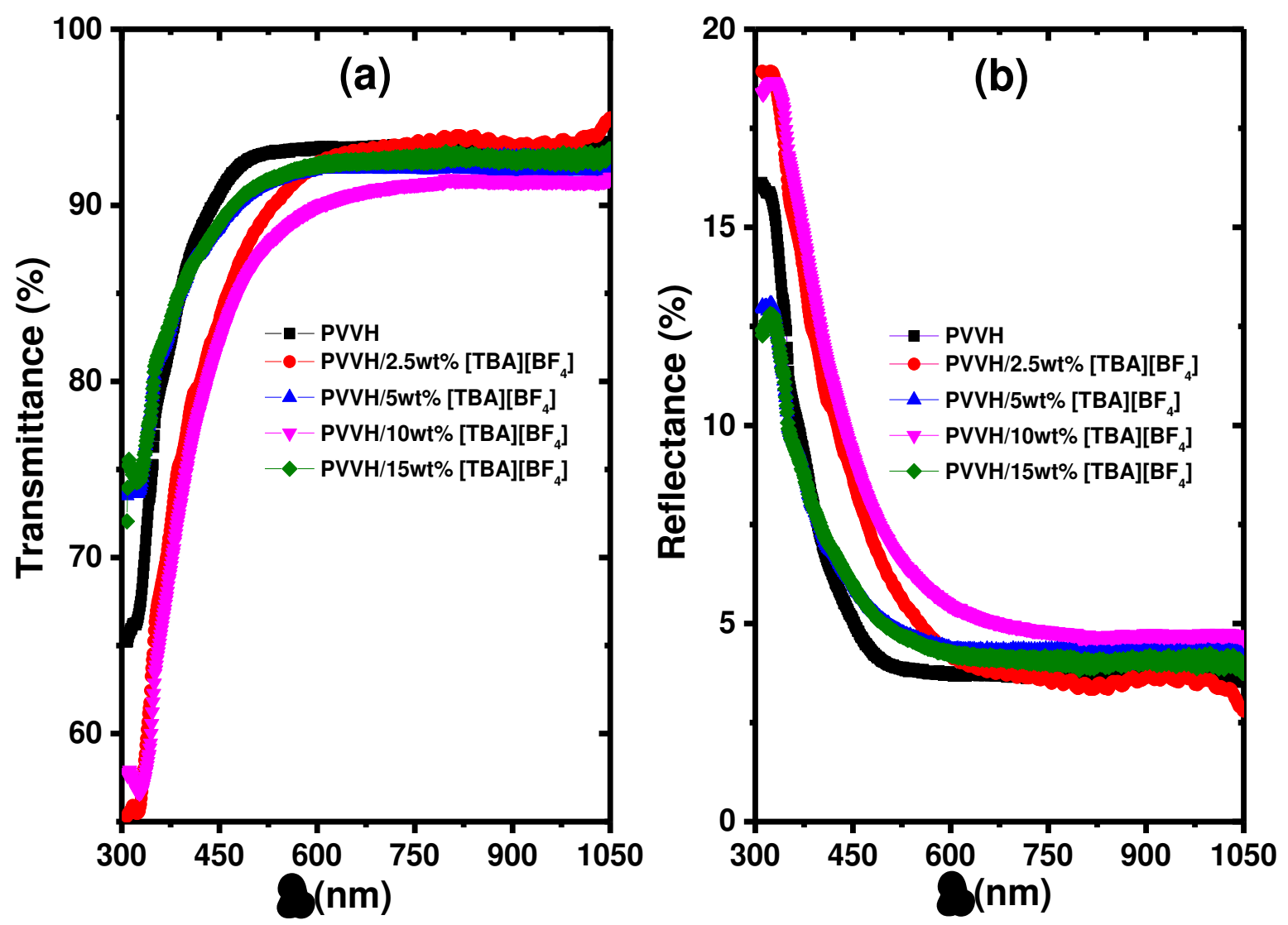

Fig. 9 The transmittance (a) and reflectance (b) versus wavelength $(\lambda)$ for pure PVVH and $\mathrm{PVVH} /[\mathrm{TBA}]\left[\mathrm{BF}_{4}\right]$ composite samples.

Fig. 9a shows that pure PVVH is an optically transparent material in visible region with a transmittance exceed 90\%. The PVVH/[TBA] $\left[\mathrm{BF}_{4}\right]$ composite samples demonstrate similar behavior however with lower values. The decrease in transmittance with increasing electrolyte content may be related to the fact that $[\mathrm{TBA}]\left[\mathrm{BF}_{4}\right]$ electrolyte acts as scattering centers in PVVH 
matrix. On the other side, the reflectance (Fig. 9b) shows opposite trend to transmission i.e., it increases with increasing electrolyte content. The variations in both the transmittance and reflectance with increasing $[\mathrm{TBA}]\left[\mathrm{BF}_{4}\right]$ content in the composite samples may be interpreted using the proportional relationship between free carrier absorption in the polymer material and the number of carriers. As the number of carriers increases, their absorption in the visible region subsequently increases.
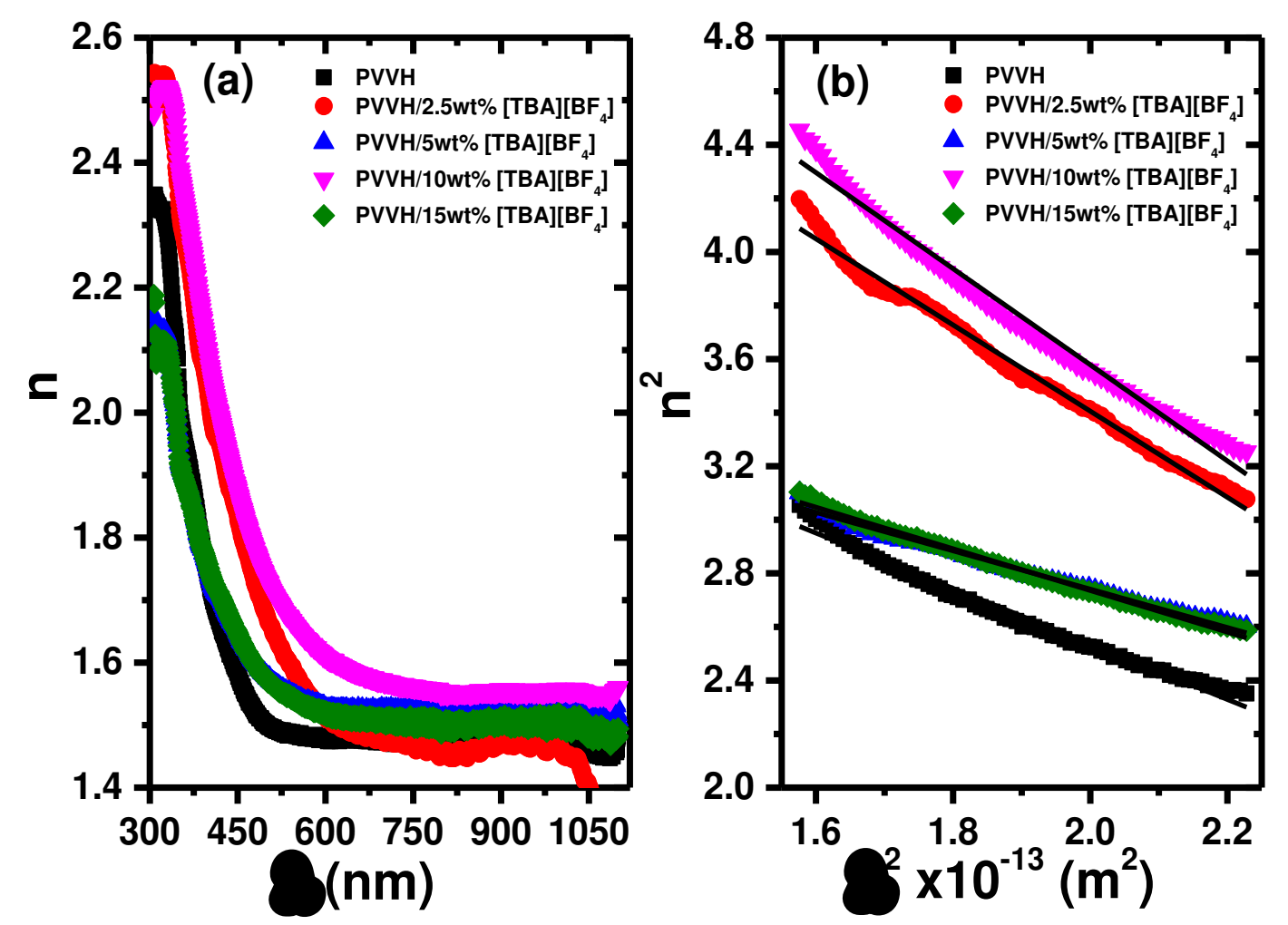

Fig. 10 a) The refractive index $(n)$ versus wavelength $(\lambda)$ for pure PVVH and $\mathrm{PVVH} /[\mathrm{TBA}]\left[\mathrm{BF}_{4}\right]$ composite samples. b) corresponding plot for $n^{2}$ versus $\lambda^{2}$.

Fig. 10a shows the dependence of refractive index on wavelength. It is observed that, the refractive index of all samples decreases with increasing wavelength until a wavelength of 500 $\mathrm{nm}$, after which the refractive index is almost unchanged. The relation between $n$ and $\lambda$ can be expressed as follows [22]

$n^{2}=\varepsilon_{L}-\frac{e^{2}}{\pi c^{2}}\left(\frac{N}{m^{*}}\right) \lambda^{2}$

where $\varepsilon_{L}, e, c$ and $\left(\mathrm{N} / \mathrm{m}^{*}\right)$ are the lattice dielectric constant, electronic charge, light speed and carrier concentration to effective mass ratio, respectively. Fig. 10b shows the variation of $n^{2}$ versus $\lambda^{2}$ for all samples. The linear fit of experimental data will give the values of $\varepsilon_{L}$ and $N / \mathrm{m}^{*}$ from which the plasma frequency $\left(\omega_{p}\right)$ is calculated based on the following equation [62] 
$\omega_{p}^{2}=\frac{e^{2}}{\varepsilon_{0}}\left(\frac{N}{m^{*}}\right)$

Where $\varepsilon_{0}$ is the permittivity of free space. The high values of plasma frequency (Table 3 ) are attributed to the high values of the free carrier concentrations.

The refractive index dispersion in $\mathrm{PVVH} /[\mathrm{TBA}]\left[\mathrm{BF}_{4}\right]$ composite samples can be modeled by the single effective oscillator model proposed by Wemple to get the dispersion energy parameters $E_{\mathrm{d}}$ and $E_{0}$ according to the following relation [63]

$$
\left(n^{2}-1\right)^{-1}=\frac{E_{0}}{E_{d}}-\frac{(h v)^{2}}{E_{o} E_{d}}
$$

Here, $E_{d}$ is the energy of dispersion, which is a measure of the strength of the oscillator or average strength of inter-band optical transitions and $E_{0}$ is the average excitation energy or the energy of a single oscillator for the electronic transition, respectively. Fig. 11 demonstrates the relation between $\left(n^{2}-1\right)^{-1}$ and $(h v)^{2}$ for all samples. The values of $E_{0}$ and $E_{d}$ are evaluated from the intercept and slope of the linear fit to data point and summarized in Table 3.
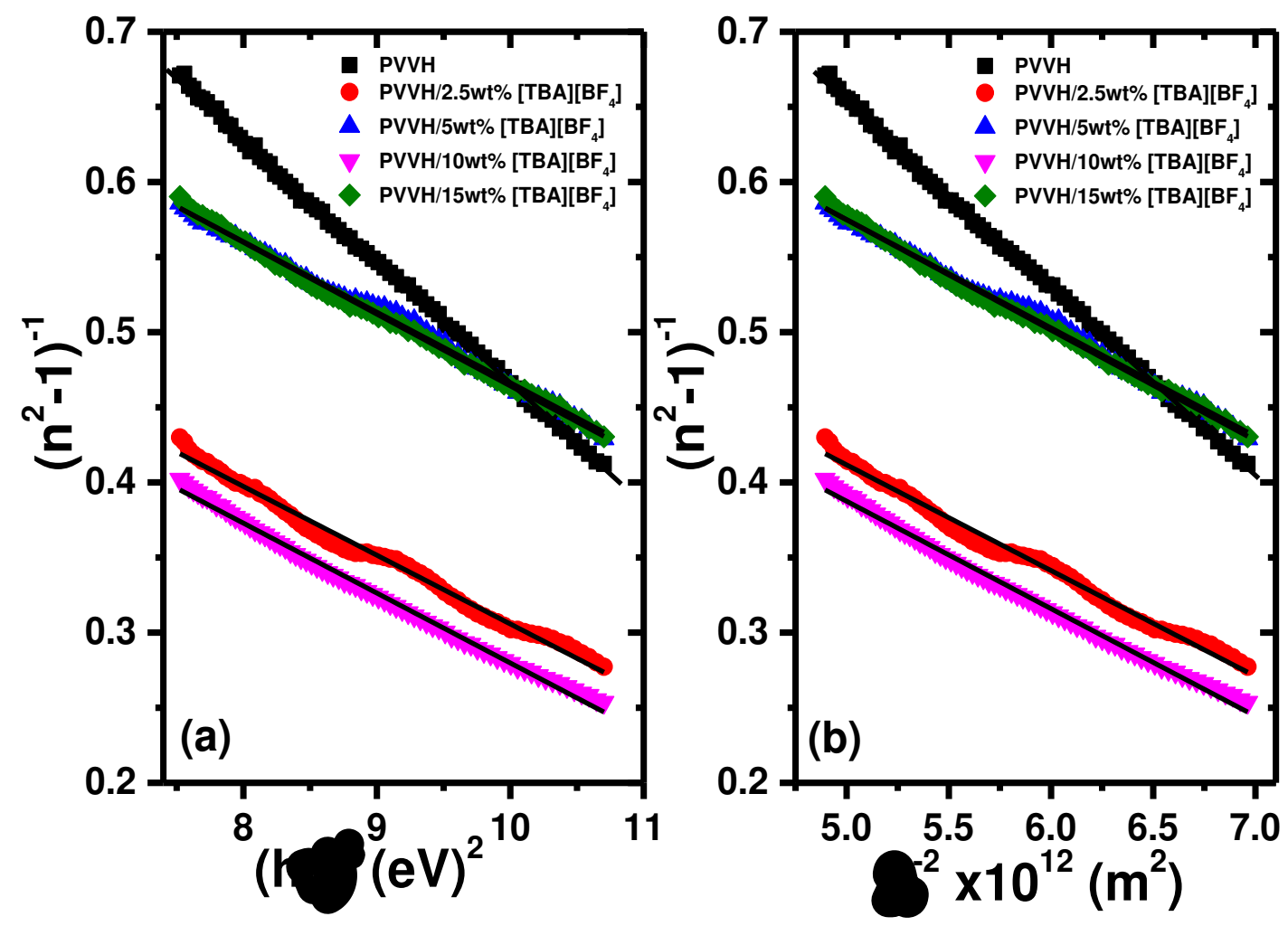

Fig. 11 a) $\left(n^{2}-1\right)^{-1}$ versus $(h v)^{2}$ and b) $\left(n^{2}-1\right)^{-1}$ versus $\left(\lambda^{-2}\right)$ for pure PVVH and $\mathrm{PVVH} /[\mathrm{TBA}]\left[\mathrm{BF}_{4}\right]$ composite samples. Solid lines represent the linear fit to data point.

The calculated values of $E_{d}$ and $E_{0}$ are used to get several optical parameters as the moments of the imaginary part of optical spectrum $\left(M_{-1}\right.$ and $\left.M_{-3}\right)$, static refractive index $\left(n_{0}\right)$, static 
dielectric constant $\left(\varepsilon_{S}\right)$ and the optical oscillator strength $F$ according to the following equations [63-65]

$$
\begin{array}{lrr}
E_{0}^{2}=\frac{M_{-1}}{M_{-3}} & \text { and } \quad E_{d}^{2}=\frac{M_{-1}^{3}}{M_{-3}} \\
n_{0}=\left(1+\frac{E_{d}}{E_{0}}\right)^{0.5}, & \varepsilon_{s}=n_{0}^{2}, \quad \text { and } & F=E_{0} E_{d}
\end{array}
$$

The values of $\varepsilon_{s}$ are lower than the corresponding ones for $\varepsilon_{L}$ (Table 3). This difference can be attributed to the contribution of polarization process that occurs inside the material when light falls on it as well as the increase in concentration of free carriers. Moreover, the increase of the electrolyte content leads to an increase of the optical oscillator strength $F$ (see Table 3), which means an increase of photon absorption by electron between the initial and final states.

The molecular polarizability $(\eta)$ and polarizability volume $\left(\eta^{\prime}\right)$ of $\mathrm{PVVH} /[\mathrm{TBA}]\left[\mathrm{BF}_{4}\right]$ composite samples can be estimated from the Clausius-Mossotti relation [66]

$$
\eta=\frac{3 M \varepsilon_{0}}{\rho N_{A}} \frac{\left(\varepsilon_{s}-1\right)}{\left(\varepsilon_{s}+2\right)} \quad \text { and } \quad \eta^{\prime}=\frac{\eta}{4 \pi \varepsilon_{0}}
$$

Here, $M\left(=33000 \mathrm{~g} \mathrm{~mol}^{-1}\right), \rho\left(=1.38 \mathrm{~g} \mathrm{~cm}^{-3}\right)$ and $N_{\mathrm{A}}$ are the molecular weight, density and Avogadro's number. The values of $\eta$ and $\eta^{\prime}$ (Table 3) increase with increasing the content of $[\mathrm{TBA}]\left[\mathrm{BF}_{4}\right]$. It is known that the electronic polarizability is related to the molecular size and symmetry of molecule i.e., polarizability volume increases with increasing molecular volume [67]. Adding [TBA] $\left[\mathrm{BF}_{4}\right]$ to $\mathrm{PVVH}$ in different concentrations leads to an increase of molecular size and subsequently an increment of polarizability volume $\left(\eta^{\prime}\right)$. The polarizability volume of $\left[\mathrm{BF}_{4}\right]$ has been reported using ab initio-based methods as HF and MP2 and found $\eta^{\prime}$ of $3.495 \times$ $10^{-30} \mathrm{~m}^{3}$ [67]. The $\eta^{\prime}$ of $\left[\mathrm{BF}_{4}\right]$ was also estimated optically using UV-vis spectroscopy and found value of $4.27 \times 10^{-29} \mathrm{~m}^{3}$ [22]. Both values are in good agreement with our results.

The dispersion equation can be expressed in terms of the single term oscillatory model as the following [68]

$\frac{1}{n^{2}-1}=\frac{1}{\left(n_{0}^{2}-1\right)}-\frac{1}{S_{0}} \frac{1}{\lambda^{2}} \quad$ and $\quad S_{0}=\frac{\left(n_{0}^{2}-1\right)}{\lambda_{0}^{2}}$

Where $S_{0}$ and $\lambda_{0}$ are the average oscillator strength and the average inter-band oscillator wavelength, respectively. These optical parameters $\left(S_{0}, \lambda_{0}\right)$ are calculated from the linear fit of the linear relationship between $\left(n^{2}-1\right)^{-1}$ and $1 / \lambda^{2}$ (Fig. $11 \mathrm{~b}$ and Table 3 ). The values of $S_{0}$ jumps from $0.81 \times 10^{13}$ to $1.42 \times 10^{13} \mathrm{~m}^{-2}$ just by adding $2.5 \mathrm{wt} \%[\mathrm{TBA}]\left[\mathrm{BF}_{4}\right]$ to $\mathrm{PVVH}$ indicating higher absorption probability in transitions between energy levels. 


\subsubsection{Nonlinear optical parameters}

Sufficient and intense illumination of the material causes nonlinear response of polarization density to the electric field of light. Determining the nonlinear optical parameters of materials is vital for the fabrication of optical switching and frequency conversion devices which are an important part of integrated photonics. Third-order nonlinear optical susceptibility $\left(\chi^{(3)}\right)$ is taken into consideration as a very important nonlinear optical parameter for many applications as telecommunication systems with high capacities [69]. According to Miller's rule, $\chi^{(3)}$ can be estimated using the following equation [70,71]

$\chi^{(3)}=A\left(\chi^{(1)}\right)^{4}$

Where $A\left(=1.79 \times 10^{-10} e s u\right)$ is a constant and $\chi^{(1)}\left(=E_{d} / 4 \pi E_{0}\right)$ is the linear optical susceptibility. Therefore, $\chi^{(3)}$ can be expressed as [71]

$$
\begin{aligned}
\chi^{(3)} & =A\left(\frac{E_{d}}{4 \pi E_{0}}\right)^{4} \\
& =\frac{A}{(4 \pi)^{4}}\left(n_{0}^{2}-1\right)^{4}
\end{aligned}
$$

The values of $\chi^{(3)}$ and $n_{0}$ (Table 3 ) are used to calculate the nonlinear refractive index $\left(n_{2}\right)$ according to the following relation [71]

$n_{2}=\frac{12 \pi}{n_{0}} \chi^{(3)}$

Surprisingly, the values of $n_{2}$ for composites is higher than the corresponding value of pristine PVVH by three to seven orders of magnitude indicating that PVVH/[TBA] $\left[\mathrm{BF}_{4}\right]$ composites could be an excellent candidate for nonlinear optical applications.

\subsubsection{Optical conductivity and optical dielectric constant}

Fig. 12a evince the frequency dependence of optical conductivity $\sigma_{o p}(=n c \alpha / 4 \pi[62])$ for pure $\mathrm{PVVH}$ and $\mathrm{PVVH} /[\mathrm{TBA}]\left[\mathrm{BF}_{4}\right]$ composite samples. It is obvious from the plot that $\sigma_{o p}$ increases with increasing both frequency and electrolyte concentration. The increase of the latter leads to an increase of the number of charge carriers in the composites and subsequently an increase in $\sigma_{o p}$ and decrease in $E_{\mathrm{g}}$. One possible reason for the increment of $\sigma_{o p}$ is that [TBA] $\left[\mathrm{BF}_{4}\right]$ electrolyte is fitted well in between the spaces of PVVH matrix creating a segregated network that results in an increase in $\sigma_{o p}$ [72]. On the other hand, the lower values of $\sigma_{o p}$ at lower frequencies may be due to the low availability of mobile charge carriers to transport from one localized state to another because of the interfacial polarization effect in this frequency region. With increasing frequency, the average displacement of charge carrier decreases and the conductivity will increase [73]. 

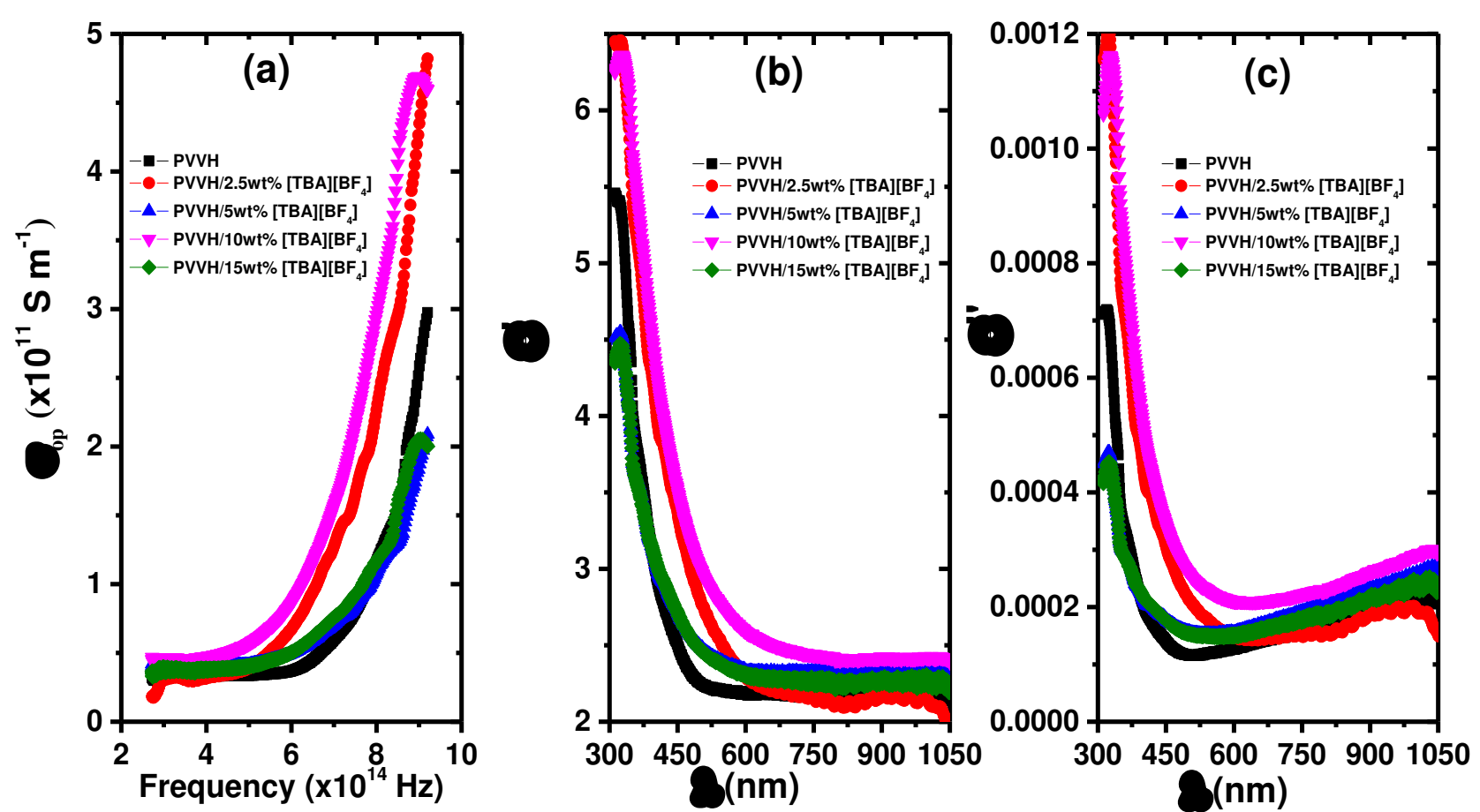

Fig. 12 a) Optical conductivity $\left(\sigma_{\mathrm{op}}\right)$ versus frequency, b) dielectric constant $\left(\varepsilon^{\prime}\right)$ versus wavelength and (c) dielectric loss $\left(\varepsilon^{\prime \prime}\right)$ versus wavelength for pure $\mathrm{PVVH}$ and $\mathrm{PVVH} /[\mathrm{TBA}]\left[\mathrm{BF}_{4}\right]$ composite samples.

The real $\left(\varepsilon^{\prime}=n^{2}-k^{2}\right)$ and imaginary $\left(\varepsilon^{\prime \prime}=2 n k\right)$ parts of the complex dielectric function ( $\varepsilon^{*}=\varepsilon^{\prime}-i \varepsilon^{\prime \prime}$ ) for PVVH and its composites are displayed in Fig. 12b and $\mathrm{c}$ as a function of wavelength. Both $\varepsilon^{\prime}$ and $\varepsilon^{\prime \prime}$ have the same trend with $\lambda$ and electrolyte concentration however with different values. They increase with increasing the electrolyte content and decrease with increasing $\lambda$. It is known that the energy density $u\left(=1 / 2 \varepsilon_{0} \varepsilon^{\prime} E_{\mathrm{b}}, E_{\mathrm{b}}\right.$ is the breakdown strength [74]) of a materials is directly proportional to its dielectric constant $\left(\varepsilon^{\prime}\right)$. That means the PVVH composites achieve higher energy densities than the corresponding pristine PVVH. Similar behavior was recently reported for polymer/ceramic composites [74]. The behavior of $\varepsilon^{\prime}$ exhibit also a wide dispersion region below $500 \mathrm{~nm}$ due to the polar nature of composites that follows the fluctuations of incident electric field. This dispersion region plays a vital role in the design of optical devices as well as in optical communication. On the other hand, at higher wavelengths the molecules cannot follow the incident field fluctuations due to the inertia and therefore $\varepsilon^{\prime}$ is almost constant. The higher values of dielectric loss $\left(\varepsilon^{\prime \prime}\right)$ at lower frequencies (Fig. 12c) is due to the dipolar polarization. The dipoles in the polymeric material at lower and intermediate frequencies can easily polarized under the external electric field that displaces the charges from their equilibrium position or traps [75]. 


\section{Conclusion}

Composites of PVVH and $\left[\mathrm{TBA}^{\mathrm{P}}\left[\mathrm{BF}_{4}\right]\right.$ electrolyte were prepared by casting method. The interaction between the two compounds was traced by ATR-FTIR and found rapid reduction in the most intense peaks located at 1666 and $1729 \mathrm{~cm}^{-1}$. These bands are related to the carbonyl groups $(\mathrm{C}=\mathrm{O})$ of VAc and 2HPA monomers. Their reduction with increasing the electrolyte content is due to the diacylation effect that eliminate acetic acid from PVVH. TGA/ DTG thermal degradation of the second stage revealed remarkable reduction in peak temperature $\left(T_{\mathrm{p}}\right)$ with increasing electrolyte content due to the dehydrochlorination and removal of acetic acid. The fast reduction in $T_{\mathrm{p}}$ suggests that $[\mathrm{TBA}]\left[\mathrm{BF}_{4}\right]$ electrolyte promotes the removal of acetic acid along with temperature. The glass transition temperature $\left(T_{\mathrm{g}}\right)$ of $\mathrm{PVVH}$ decreases by $34 \mathrm{~K}$ as the electrolyte concentration increase by $20 \mathrm{wt} \%$ indicating more flexibility of the polymer chain. One possible reason for the reduction in $T_{\mathrm{g}}$ is that deacetylation change the PVVH conformation by reducing the inter- and intramolecular interaction maintaining flexibility of polymer backbone to bend and slide more readily. The linear correlation between activation energy and frequency factor indicates that these composites demonstrate compensation effect with $k_{\text {iso }}$ and $T_{\text {iso }}$ of $3.46 \times 10^{-5} \mathrm{~s}^{-1}$ and $442.9 \mathrm{~K}$, respectively

$\mathrm{UV}$-vis measurements for PVVH and its composites revealed reduction in the absorption edge $\left(E_{\text {edge }}\right)$, direct $\left(E_{\mathrm{g} \text {-direct }}\right)$ and indirect $\left(E_{\mathrm{g} \text {-direct }}\right)$ optical band gap with increasing the electrolyte content. This reduction owed to the formation of charge transfer complexes by the dopant that increases the optical conductivity $\left(\sigma_{\mathrm{op}}\right)$ by giving additional charges to the polymer matrix. Also, the real $\left(\varepsilon^{\prime}\right)$ and imaginary $\left(\varepsilon^{\prime \prime}\right)$ parts of the complex dielectric function were found to decrease with increasing wavelength. Linear and nonlinear optical parameters were estimated and discussed in terms of the single term Sellmeier oscillator model for possible application in optical components and devices.

\section{Acknowledgement}

Authors express their appreciation to the Deanship of Scientific Research at Prince Sattam bin Abdulaziz University in Saudi Arabia for financial support under grant number 2020/01/17195.

\section{Conflict of interest}

The authors declare that they have no conflict of interest. 


\section{References}

1. A. Dawelbeit and M. Yu, Materials (Basel). 14, 2938 (2021).

2. K. S. Ngai, S. Ramesh, K. Ramesh, and J. C. Juan, Ionics (Kiel). 22, 1259 (2016).

3. W. Li, Y. Pang, J. Liu, G. Liu, Y. Wang, and Y. Xia, RSC Adv. 7, 23494 (2017).

4. C. Sequeira and D. Santos, Polymer Electrolytes: Fundamentals and Applications, 1st Ed. (Woodhead Publishing Limited, 2010).

5. F. Jäkle, Chem. Rev. 110, 3985 (2010).

6. L. H. Slooff, A. Van Blaaderen, A. Polman, G. A. Hebbink, S. I. Klink, F. C. J. M. Van Veggel, D. N. Reinhoudt, and J. W. Hofstraat, J. Appl. Phys. 91, 3955 (2002).

7. A. Y. Yassin, A. M. Abdelghany, M. M. Shaban, and Y. M. Abdallah, Colloids Surfaces A Physicochem. Eng. Asp. 635, 128115 (2022).

8. L. Zhang, J.-H. Yang, X.-Y. Wang, X. He, B. Zhao, Z.-H. Tang, G.-Z. Yang, and H.-X. Qiu, Chinese Phys. Lett. 28, 016501 (2011).

9. N. S. Schauser, A. Nikolaev, P. M. Richardson, S. Xie, K. Johnson, E. M. Susca, H. Wang, R. Seshadri, R. ele J. Clement, J. R. de Alaniz, and R. A. Segalman, ACS Macro Lett. 10, 104 (2021).

10. D. K. Pradhan, R. N. P. Choudhary, B. K. Samantaray, N. K. Karan, and R. S. Katiyar, Int. J. Electrochem. Sci. 2, 861 (2007).

11. J. Imbrogno, K. Maruyama, F. Rivers, J. R. Baltzegar, Z. Zhang, P. W. Meyer, V. Ganesan, S. Aoshima, and N. A. Lynd, ACS Macro Lett. 10, 1002 (2021).

12. B. K. Money, K. Hariharan, and J. Swenson, J. Phys. Chem. B 116, 7762 (2012).

13. M. R. R. Prasad, K. Krishnan, K. N. Ninan, and V. N. Krishnamurthy, Thermochim. Acta 297, 207 (1997).

14. S. Ramesh, S. C. Lu, and E. Morris, J. Taiwan Inst. Chem. Eng. 43, 806 (2012).

15. R. Biczak, B. Pawłowska, M. Płatkowski, M. Stręk, and A. Telesiński, Bull. Environ. Contam. Toxicol. 98, 567 (2017).

16. M. Ahmed and T. Fahmy, J. Korean Phys. Soc. 59, 98 (2011).

17. T. Fahmy, Polym. Plast. Technol. Eng. 46, 7 (2007).

18. M. Ahmed and T. Fahmy, Polym. Plast. Technol. Eng. 44, 1559 (2005).

19. T. Fahmy, A. Sarhan, I. A. Elsayed, and H. G. Abdelwahed, Int. J. Eng. Res. Technol. 11, 1405 (2018).

20. A. M. Abdelghany, M. A. Morsi, and A. Abdelrazek, Silicon 10, 1697 (2018).

21. A. Y. Yassin, A. R. Mohamed, E. M. Abdelrazek, M. A. Morsi, and A. M. Abdelghany, J. Mater. Res. Technol. 8, 1111 (2019). 
22. M. M. Elmahdy, T. Fahmy, K. A. Aldhafeeri, E. O. Ibnouf, and Y. Riadi, Mater. Chem. Phys. 264, 124369 (2021).

23. G. Socrates, Infrared and Raman Characteristic Group Frequencies: Tables and Charts (John Wiley and Sons Inc., 2004).

24. E. Ruckenstein and Y. Yuan, Polymer (Guildf). 38, 3855 (1997).

25. E. Vargün and A. Usanmaz, J. Polym. Sci. Part A Polym. Chem. 43, 3957 (2005).

26. L. Costa, M. Avataneo, P. Bracco, and V. Brunella, Polym. Degrad. Stab. 77, 503 (2002).

27. M. Füllbrandt, P. J. Purohit, and A. Schönhals, Macromolecules 46, 4626 (2013).

28. Q. Ma, X. Gao, X. Bi, Q. Han, L. Tu, Y. Yang, Y. Shen, and M. Wang, Carbohydr. Polym. 230, 115605 (2020).

29. M. R. Jung, F. D. Horgen, S. V. Orski, V. Rodriguez C., K. L. Beers, G. H. Balazs, T. T. Jones, T. M. Work, K. C. Brignac, S. J. Royer, K. D. Hyrenbach, B. A. Jensen, and J. M. Lynch, Mar. Pollut. Bull. 127, 704 (2018).

30. G. Sivalingam, R. Karthik, and G. Madras, Ind. Eng. Chem. Res. 42, 3647 (2003).

31. Z. Xu, S. S. Kolapkar, S. Zinchik, E. Bar-Ziv, and A. G. McDonald, Polym. Degrad. Stab. 176, 109148 (2020).

32. M. S. Abbas-Abadi, J. Therm. Anal. Calorim. 143, 2867 (2021).

33. A. Marongiu, T. Faravelli, G. Bozzano, M. Dente, and E. Ranzi, J. Anal. Appl. Pyrolysis 70, 519 (2003).

34. S. M. Kuznetsov, E. A. Sagitova, K. A. Prokhorov, G. Y. Nikolaeva, D. I. Mendeleev, P. Donfack, and A. Materny, Spectrochim. Acta Part A Mol. Biomol. Spectrosc. 252, 119494 (2021).

35. D. Torres, Y. Jiang, D. A. Sanchez-Monsalve, and G. A. Leeke, J. Anal. Appl. Pyrolysis 149, 104831 (2020).

36. J. Zhou, G. Liu, S. Wang, H. Zhang, and F. Xu, J. Energy Inst. 93, 2362 (2020).

37. M. N. Radhakrishnan Nair, G. V. Thomas, and M. R. Gopinathan Nair, Polym. Degrad. Stab. 92, 189 (2007).

38. M. Akçay, J. Colloid Interface Sci. 296, 16 (2006).

39. J. De La Zerda, R. Neumann, and Y. Sasson, J. Chem. Soc. Perkin Trans. 2823 (1986).

40. K. H. Sjoholm, M. Cooney, and S. D. Minteer, Carbohydr. Polym. 77, 420 (2009).

41. P. H. Daniels, J. Vinyl Addit. Technol. 15, 219 (2009).

42. P. W. Skelly, L. Li, and R. Braslau, Polym. Rev. (2021).

43. T. Rezende, C. Abreu, A. Fonseca, C. Higa, L. Li, A. Serra, R. Braslau, and J. Coelho, Poymer 196, (2020). 
44. L. Li, A. Tek, R. Wojtecki, and B. Rebecca, J Polym Sci A Polym Chem . 57, 1821 (2019).

45. Y. Ma, S. Liao, Q. Li, Q. Guan, P. Jia, and Y. Zhou, React. Funct. Polym 147, 104458 (2020).

46. J. Czogała, E. Pankalla, and R. Turczyn, Materials (Basel). 14, 1 (2021).

47. R. Navarro, M. Pérez Perrino, C. García, C. Elvira, A. Gallardo, and H. Reinecke, Macromolecules 49, 2224 (2016).

48. R. Navarro, T. Gacal, M. Ocakoglu, C. García, C. Elvira, A. Gallardo, and H. Reinecke, Macromol. Rapid Commun. 38, 1600734 (2017).

49. L. T. Vlaev, I. G. Markovska, and L. A. Lyubchev, Thermochim. Acta 406, 1 (2003).

50. H. L. Friedman, J. Polym. Sci. Part C Polym. Symp. 6, 183 (1964).

51. A. W. Coats and J. P. Redfern, Nature 201, 68 (1964).

52. S. Altarawneh, M. Al-Harahsheh, C. Dodds, A. Buttress, and S. Kingman, Thermochim. Acta 707, 179105 (2022).

53. R. K. Agrawal, J. Therm. Anal. Calorim. 31, 73 (1986).

54. L. Liu and Q. X. Guo, Chem. Rev. 101, 673 (2001).

55. M. D. Migahed, M. T. Ahmed, and A. E. Kotp, J. Phys. D Appl. Phys. 33, 2108 (2000).

56. J. Tauc and A. Menth, J. Non. Cryst. Solids 8-10, 569 (1972).

57. F. Urbach, Phys. Rev. 92, 1324 (1953).

58. N. F. Mott and E. A. Davis, Electronic Processes in Non-Crystalline Materials, 2nd Ed. (Oxford University Press Inc., 1979).

59. J. Tauc, R. Grigorovici, and A. Vancu, Phys. Status Solidi 15, 627 (1966).

60. C. U. Devi, A. K. Sharma, and V. V. R. N. Rao, Mater. Lett. 56, 167 (2002).

61. J. I. Pankove, Optical Processes in Semiconductors (Prentice-Hall, Inc. Englewood Cliffs, N. J., 1971).

62. F. Wooten, Acad. Press. Inc. (1972).

63. S. H. Wemple, Phys. Rev. B 7, 3767 (1973).

64. S. H. Wemple and M. Didomenico, Phys. Rev. Lett. 23, 1156 (1969).

65. S. H. Wemple and M. DiDomenico, Phys. Rev. B 3, 1338 (1971).

66. P. Atkins and J. de Paula, Oxford Univ. Press (2010).

67. E. I. Izgorodina, M. Forsyth, and D. R. MacFarlane, Phys. Chem. Chem. Phys. 11, 2452 (2009).

68. P. A. Lee, G. Said, R. Davis, and T. H. Lim, J. Phys. Chem. Solids 30, 2719 (1969).

69. D. Cotter, R. J. Manning, K. J. Blow, A. D. Ellis, A. E. Kelly, D. Nesset, I. D. Phillips, A. J. Poustie, and D. C. Rogers, Science (80-. ). 286, 1523 (1999).

70. R. W. Boyd, Nonlinear Optics (Academic Press, 2020). 
71. H. Tichá and L. Tichýa, J. Optoelectron. Adv. Mater. 4, 381 (2002).

72. N. Sharma, S. Sharda, V. Sharma, and P. Sharma, Mater. Chem. Phys. 136, 967 (2012).

73. Z. Jin, D. Gehrig, C. Dyer-Smith, E. J. Heilweil, F. Laquai, M. Bonn, and D. Turchinovich, J. Phys. Chem. Lett. 5, 3662 (2014).

74. G. Jian, Y. Jiao, L. Feng, Q. Meng, N. Yang, S. Zhu, M. Lü, and C. P. Wong, NPG Asia Mater. 14, 1 (2022).

75. F. Kremer and A. Schönhals, Broadband Dielectric Spectroscopy (Springer-Verlag Berlin Heidelberg GmbH, 2002). 


\section{Supplementary Files}

This is a list of supplementary files associated with this preprint. Click to download.

- GraphicalAbstract.docx 